Andrews University

Digital Commons @ Andrews University

1994

\title{
A Study of Post-Traumatic Stress Disorder Among Resettled and Refugee Cambodians
}

Jolene Malinee Aitken

Andrews Uiniversity, roosenberg@andrews.edu

Follow this and additional works at: https://digitalcommons.andrews.edu/theses

Part of the Education Commons, Social Psychology Commons, and the Social Work Commons

\section{Recommended Citation}

Aitken, Jolene Malinee, "A Study of Post-Traumatic Stress Disorder Among Resettled and Refugee Cambodians" (1994). Master's Theses. 167.

https://dx.doi.org/10.32597/theses/158

https://digitalcommons.andrews.edu/theses/167

This Thesis is brought to you for free and open access by the Graduate Research at Digital Commons @ Andrews University. It has been accepted for inclusion in Master's Theses by an authorized administrator of Digital Commons@ Andrews University. For more information, please contact repository@andrews.edu. 


\begin{abstract}
A STUDY OF POST-TRAUMATIC STRESS DISORDER AMONG REFUGEE AND RESETTLED CAMBODIANS
\end{abstract}

by

Jolene Malinee Aitken

Chair: Jimmy Kijai 


\section{ABSTRACT OF GRADUATE STUDENT RESEARCH}

Thesis

Andrews University

School of Education

\section{Title: A STUDY OF POST-TRAUMATIC STRESS DISORDER AMONG REFUGEE AND RESETTLED CAMBODIANS}

Name of researcher: Jolene Malinee Aitken

Name and degree of faculty chair: Jimmy Kijai, Ph.D.

Date completed: June 1994

\section{Problem}

With the onset of the Cambodian holocaust, as well as over 40 years of continual war in Cambodia, the Khmer people have been subjected to an existence of prolonged exposure to disaster, contributing to the alarming prevalence of the mental health disorder of post-traumatic stress among Cambodians today. Post-traumatic stress disorder is the debilitating syndrome described as the development of characteristic symptoms following a psychologically traumatic event that is generally outside the range of usual human experience (Diagnostic and Statistical Manual of Mental Disorders, 3rd edition revised, [DSM-III-R], 1987). The purpose of this study was to examine the existence and evidence of this disorder among refugee and resettled Cambodians with attention given to the established themes that affect the manifestation of post-traumatic stress. 
Method

As little has been published in the area, the diagnostic parameters from the DSM-III-R and research of post-traumatic stress disorder among Vietnam veterans were used as a background and a base for the present study. Interviews with the Indochinese located along the Thailand border refugee camps, phenomenological interviews conducted among resettled refugees, as well as follow-up interviews conducted 2 years following initial interviews were the way this study was operationalized.

\section{Results}

Findings include an exploration of post-traumatic stress disorder, with evidence of the alarming degree to which the disorder is experienced. The results from the informal surveys in Thailand refugee camps include evidence of all subjects suffering from PTSD. The indepth phenomenological interviews also indicate evidence that those interviewed suffer from PTSD. Theme relating to PTSD symptoms include (1) adjustment and resettlement issues continue to face resettled Cambodians, compounding PTSD symptoms, (2) a wide variety fo symptoms of PTSD exist and are exhibited to varying degrees by Cambodians, (3) family in all respects is of utmost importance and is a major source of support and strength in coping with PTSD symptomology, (4) a belief in spiritual issues influences in multiple ways, guiding, aiding, offering peace and hope in coping with PTSD, (5) issues of trust and mistrust confront resettled Cambodians as a byproduct of past trauma, and (6) the future is extremely important and is used as a coping mechanism to deal with PTSD symptoms. 


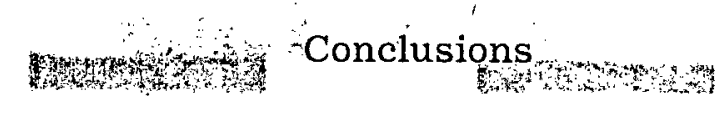

Post-traumatic stress disorder among resettled and refugee

Cambodian victims of prolonged trauma proves to be a serious mental health concern. In an effort to better understand post-traumatic stress disorder as it relates to Cambodian trauma victims, Western assumptions and values regarding the manifestation of symptoms, the utilization of mental health services and attitudes toward counseling must be understood in light of eastern experiences, views, and culture. To aid in this understanding, analysis of in-depth, phenomenological interviews provides information and an overview of post-traumatic stress disorder among Cambodians. It is only then that service providers can utilize effective healing and intervention in working with Cambodian victims of post-traumatic stress disorder. 
Andrews University

School of Education

A STUDY OF POST-TRAUMATIC STRESS DISORDER AMONG RESETTLED AND REFUGEE CAMBODIANS

\author{
A Thesis \\ Presented in Partial Fulfillment \\ of the Requirements for the Degree \\ Master of Arts
}

by

Jolene Malinee Aitken

1994 

A STUDY OF POST-TRAUMATIC STRESS DISORDER

AMONG REFUGEE AND RESETTLED CAMBODIANS

A thesis

presented in partial fulfillment

of the requirements for the degree

Master of Arts

by

Jolene Malinee Aitken

APPROVAL BY THE COMMITTEE:
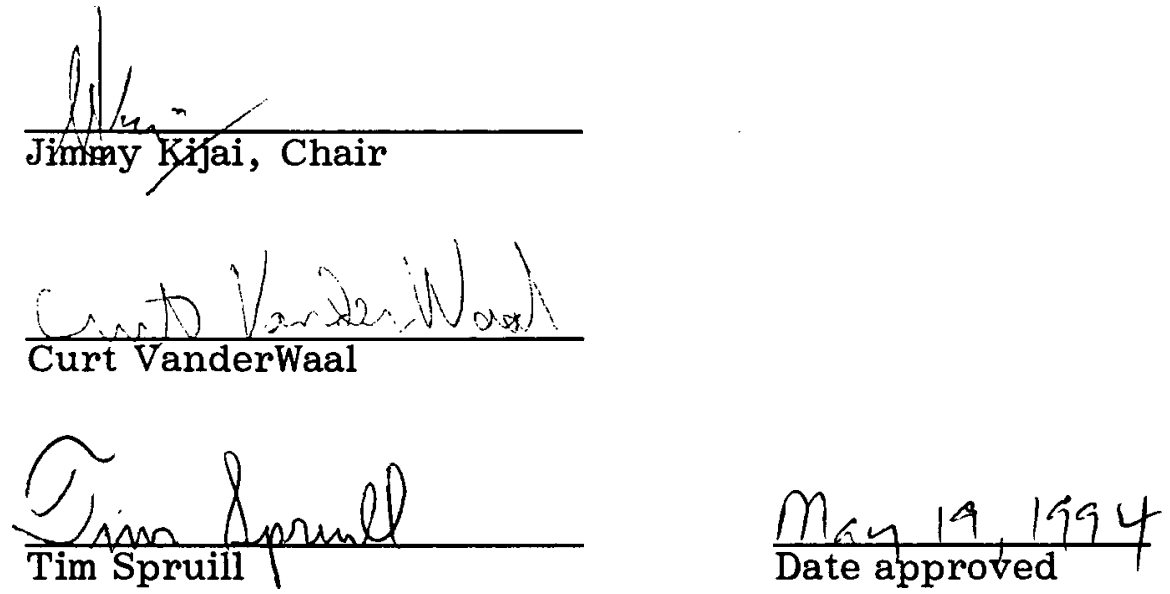


\section{TABLE OF CONTENTS}

LIST OF TABLES ...................... . . . . .

ACKNOWLEDGMENTS ............................. vi

Chapter

I. INTRODUCTION .................... 1

Historical Review ................ 2

Refugee Camp Realities ............. 5

Current Cambodia ............... . . 6

Rationale and Significance ............ 8

Statement of the Problem ............. 10

Definition of PTSD .............. 10

Outline of the Thesis ............... 11

II. LITERATURE REVIEW .................. 13

Resettlement Process .............. 17

Summary of the Literature . . . . . . . . . . 21

III. METHODOLOGY . . . . . . . . . . . . . . . 22

Type of Research ................. 22

Limitations of Methodology . . . . . . . . . . 25

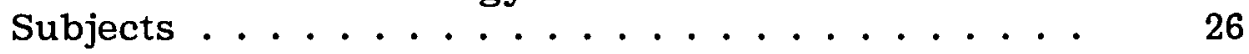

Thailand Surveys ............. 26

Initial U.S. Phenomenological Interviews . . . . 27

Follow-up Phenomenological Interviews . . . . . 28

Procedure ................... . . . 29

Thailand Surveys . . . . . . . . . . . 29

Initial U.S. Phenomenological Interviews . . . . 32

Follow-up Phenomenological Interviews . . . . 36

Data Analysis of Initial and Follow-up

Phenomenological Interviews .......... 37

Summary of Methodology .............. 38

IV. RESULTS .......................... 40

Results from Informal Thailand Survey . . . . . . . 41

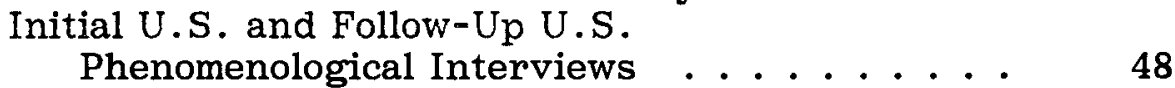

Initial Interview Results . . . . . . . . . . . 51 
Follow-up Interview Results . . . . . . . . . . 57

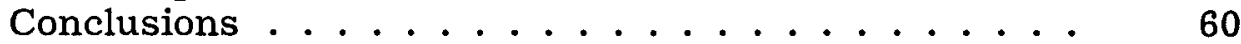

V. DISCUSSION AND CONCLUSIONS ............ 63

Discussion of Results ............. 63

Informal Thailand Survey ........... 63

Initial U.S. Interviews . . . . . . . . . . 69

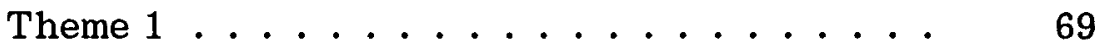

Theme $2 \ldots \ldots 72$

Theme $3 \ldots \ldots 73$

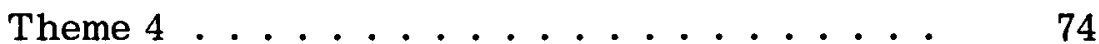

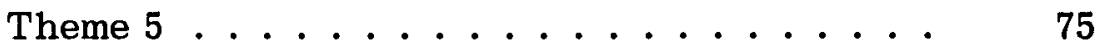

Theme 6 ...................... 75

Follow-up Phenomenological Interviews . . . . . 75

Cambodian Trauma Related to the Veteran's Trauma 78

Limitation of the Study ............ 79

Recommendations and Conclusions ....... 80

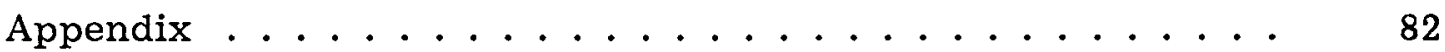

A. REFUGEE CAMP PASS .................... 83

B. INITIAL INTERVIEW AND FOLLOW-UP QUESTIONS . . . . 84

Initial Phenomenological Focus Questions . . . . . 85

Follow-up Phenomenological Focus Questions ..... 87

C. THICK DESCRIPTIONS .............. 90

Initial Interview Subject A . . . . . . . . . 91

Initial Interview Subject B ............. 101

Initial Interview Subject C . . . . . . . . . . 107

Follow-up Interview Subject A ........... 110

Follow-up Interview Subject B ........... 117

Follow-up Interview Subject C . . . . . . . . 126

REFERENCE LIST . . . . . . . . . . . . . . 134 


\section{LIST OF TABLES}

1. Symptoms Reported by Cambodian Refugees, Subjects A to I

2. Symptoms Reported by Cambodian Refugees, Subjects $J$ to $R$

3. Percentage of Reported Symptoms by Cambodian Refugees . .

4. Meaning Units and Themes Presented From

Phenomenological Interviews . . . . . . . . . . .

5. DSM-III-R Classified Symptoms Reported by Subject A

During the Initial Phenomenological Interview . . . . . .

6. DSM III-R Classified Symptoms Reported by Subject B During the Initial Phenomenological Interview . . . . . .

7. DSM-III-R Classified Symptoms Reported by Subject C During the Initial Phenomenological Interview . . . . . .

8. DSM-III-R Classified Symptoms Reported by Subject A During the Follow-up Phenomenological Interview . . . . .

9. DSM-III-R Classified Symptoms Reported by Subject B During the Follow-up Phenomenological Interview . . . . .

10. DSM-III-R Classified Symptoms Reported by Subject C During the Follow-up Phenomenological Interview . . . . . 


\section{ACKNOWLEDGMENTS}

I would like to say "thank you" to all the people who made this study possible, some of whom include the following:

To Dr. Kijai, for his time invested in the study.

To Mr. VanderWaal, for his thorough work with and interest in the study as well as the time he invested in the study and for believing in me.

To my wonderful mom, Judy Aitken, and my grandparents, Dr. and Mrs. Boyde Olson, for their prayers and support.

To my dear LWDDKWL, John M. Roosenberg II, for his dedication and computer skills.

To a great brother for his detailed check of the references.

To my dad and sister for their encouragement.

And finally, to those subjects who dedicated so much time and emotional energy in participation of the phenomenological interviews. 


\section{CHAPTER ONE}

\section{INTRODUCTION}

It is estimated that 1.5 million to 3 million Khmer people in a population of 7 million were brutally massacred by the Khmer Rouge under the Pol Pot regime between 1975 and 1979 (Kiljunen, 1985; Kinzie, Fredrickson, Ben, Fleck, \& Karls, 1984). Malnutrition, separation from families, forced labor, exhaustion, starvation, and the indescribable horror of literally seeing loved ones murdered were common experiences among those who survived. Forever etched into Indochina's history is the silent execution of the Cambodian holocaust.

The Vietnamese invasion of Cambodia (also known as Kampuchea), the onset of the Chinese communists' acquisition of government control in 1975, and guerilla warfare resulted in many Cambodians risking dangerous escapes in an attempt to flee the bloodbath to the safety of refugee camps located along the Thailand-Cambodian border. From these refugee camps, over 700,000 Indochinese have been resettled in the United States since 1975 (Mollica et al., 1990), but not before enduring protracted stays in the camps while waiting for acceptance. In addition to the stress of resettlement, many Cambodians had earlier suffered extended exposure to trauma. They witnessed atrocities, and were victims of violence and horrific experiences, often including harrowing escapes; then they had to encure the refugee camps. Consequently, most, if not all, adult Cambodian 
refugees exhibit severe symptoms of the mental health problem of posttraumatic stress disorder as a result of these prolonged traumas.

The scope of mental health problems associated with refugee and resettled Cambodians is very broad, with all bio-psycho-social factors coming into play to contribute to high stress levels. However, this study was restricted to the discussion of the prevalent psychological problem of post-traumatic stress experienced by the refugees upon their resettlement to the United States as well as while living in the refugee camps of Thailand prior to resettlement or repatriation.

\section{$\underline{\text { Historical Review }}$}

Thailand is located in Southeast Asia. Indochina lies to the east of Thailand and is comprised of Laos, Cambodia, and Vietnam. The refugees escaped from these countries in flight to the asylum of Thailand refugee camps in 1979. All who managed to escape the horror brought with them their own unique, personal nightmare of experiences. Fearful, distrustful, and silent, they sought safety in the refugee camps living in uncertainty, some anticipating resettlement in an accepting country . Thousands remained in this state until forced repatriation to Cambodia occurred in 1993.

The small country of Cambodia was once prosperous and peaceful; however, "in recent history, local, regional, and global interests have made Kampuchea a contesting ground for rival powers. It has suffered numerous wars, coups, invasions, despotic regimes, genocide, and devastating famine" (Mysliwiec, 1988, p. 2). Between the years of 1969 and 1973 leading up to the dictator Pol Pot's reign beginning in 1975, the U.S. suspected Cambodia of harboring a Vietnamese stronghold within its 
borders. As a result, claiming it was an "accident," "the U.S. dropped an estimated 550,000 tons of bombs on Kampuchea--a tonnage equivalent to about 120 of the atomic bombs that devastated Hiroshima. Also, nearly half the population was uprooted and became refugees within their own country" (Evans \& Rowley, 1984, p. 179). At this time, Pol Pot's forces were fighting alongside the Vietcong, against the U.S.-backed Lon Nol regime. Careless policies of the White House, in particular of Richard Nixon and Henry Kissinger, were in good part responsible for the disasters that befell Cambodia in the 1970s (Shawcross, 1979). The U.S. destruction of the country, along with the withdrawal of the U.S. and communist Vietnamese, left Cambodia "free" for new leadership. It was against this background of political unrest, confusion, and bloody turmoil that Pol Pot with his little band of Khmer Rouge soldiers headed the ultimate revolution and came to power in Cambodia on April 17, 1975. Within a day after taking over Phnom Penh, the capital of Cambodia, this clique began the systematic evacuation of the entire city (McWilliams \& Piatrowski, 1990). Without warning, $21 / 2$ million people were forced at gunpoint into the countryside and to villages of origin. In her book, The Stones Cry Out, Molyda Szymusiak (1986) describes this experience:

I remember fires everywhere, explosions in every part of the city. In the midst of the ruins, on the edge of what had been a street, I could see corpses lying here and there. With the heat, dust, and smell of decay, there were innumerable flies swirling around my head. (p. 7)

The French priest, Francois Ponchaud (1978), who stayed behind in Cambodia until May 6, 1975, was eyewitness to the evacuation and describes seeing the sick and injured being forced to get up and stagger from the city. 
Overnight, the country was changed from being the jewel of the Orient into a slaughter house, where rice paddies became vast killing fields. Confusion resulted in families being split up--males and females sent to separate work camps, and children taken to communes away from parents--and all ages forced into village concentration work camps, often working up to 14-hour-days with little food. Any questioning or refusal was met with instant execution. This was the start of a new regime where all would be turned back to year zero.

The aim of the Khmer Rouge leader, Pol Pot, was to create a rural utopia where all religions and social and family ties would be eliminated to be replaced by a new order. "The Khmer Rouge wiped out the country's education system, exterminating 15,000 of Cambodia's 20,000 teachers. They also destroyed the medical profession. Four out of five doctors were eliminated" (Whitaker, Clifton, \& Moreau, 1985, p. 13). Cambodia's revolution is called by author and Cambodian expert, Becker (1986), as "one of the most radical and murderous in history" (p. 21).

Following the communist Russian and Chinese philosophy, many of the same errors made during the rule of these leaderships were repeated by the Khmer Rouge; however, "what marks them as unique was their willingness to take every policy to its limit and beyond, pushing the people, themselves, and their country until it broke apart (Becker, 1986, p. 201).

The effects of the revolution were devastating and cruel. Conditions in the new Kampuchea under the Khmer Rouge (or Angka) were inhumane. Sent out at random to primitive communal villages to work in concentration camps, with long hours, little food, and hard work, 
thousands died from malnutrition and disease. "Officials, intellectuals, and professionals were eradicated--marched out of villages and usually clubbed to death. In the name of 'Angka's will', people were killed for nothing more serious than looking intelligent" (Schanberg, 1983, p. 7).

These executions were carried out with all of the hallmarks of the Khmer Rouge. There were no pretenses of justice, no show trials, no people's juries. Instead, they were lured to their death by trickery and deception. They were killed in the shadows. The Khmer Rouge did not want the executions made public. They hid the deaths from the people and denied them if asked. The cycle of revolution/purging of counterrevolution was filed with just such secret, brutal deaths. (Becker, 1986, p. 207)

More and more people began to risk the dangerous, of ten fatal, escape to the border of Thailand to live in refugee camps the Thai government was forced to construct to deal with the crisis. The news of the atrocities committed by the Khmer Rouge then began to leak out to the rest of the world. News of the shallow, mass graves of hundreds of thousands of butchered Cambodians, called the killing fields, hit the press and the Westernized countries were alerted.

\section{Refugee Camp Realities}

It has been estimated that approximately 3 million Indochinese fled to the safety of Thailand refugee camps (French, 1990). In an effort to accommodate the situation, refugee camps, unplanned and hurriedly erected, were built by the Thailand government to house the refugees. Meant to be temporary until they were accepted for resettlement, the conditions proved to be unsanitary, over-crowded, and prison-like. While one study found that exposure to traumatic events declined noticeably after arrival at the refugee camps, lack of food, torture, beatings, lack of shelter, forced evacuation, and exposure to combat situations and shelling 
attacks were still experienced (Mollica et al., 1990). The extent to which these people suffered after reaching "freedom" is also reflected in the New York Times report as follows:

There have been suicides, and attempted suicides, murders, thievery, assaults and rapes at Site 2, according to Cambodian exiles and the aid workers who feed, clothe, and shelter them and care for their health. Less dramatic but of equal concern, they add, are the mounting tensions and frustrations among people who have no place to go, "We have attempted to meet their physical needs," a European aid official said, "but emotionally, they grow sicker." (Patterson, 1989, p. 2)

With little food and in critical need of clothing, many of these people lived for up to 15 years in the refugee camps. Children were born and families raised in these conditions. Waiting in uncertainty as to what the future would hold, they sat with their memories and nightmares. They lived from day to day trying to fight the personal, internal battle of the effects of the trauma of war. As one refugee camp occupant, a young gentleman in his $30 \mathrm{~s}$, reported, "I have had two children born in the refugee camps. I want them to get away from the blackness and painful memories of the mind that I suffer" (personal communication, Chantara Ahn, October, 1991).

Due to lessened political strife and unrest in Cambodia, repatriation was begun for those living in the refugee camps along the Thai-Cambodian border. By March, 1993, over 300,000 Cambodian refugees were repatriated, and the last camp, Site II, was permanently closed (United Nations, 1993).

\section{Current Cambodia}

The weakened, unstable current political situation in Cambodia only served to compound and prolong problems of the past. On October 23, 1991, a peace agreement was signed and "includes a provision for United 
Nations sponsored elections. Prince Norodom Sihanouk, Chairman of the Supreme National Council, arrived back in Phnom Penh on 14th November 1991" (Ministry of Health, 1992, p. 1). Cambodia is now a free government.

In July, 1989 the National Assembly changed the name of the country from the People's Republic of Kampuchea to the State of Cambodia and adopted a new constitution which declares the country to be independent, sovereign, peaceful, democratic, and neutral and nonaligned. (UNICEF, 1990, p. 4)

However, as of the end of April 1994, guerilla warfare continued on the outskirts of Cambodian villages. Indeed, the Khmer Rouge have full control of nearly $10 \%$ of the country, including entire villages and provinces, even though they have been weakened by numerous losses, and now only make up nearly 9,000 men (McNulty, 1994, p. 7). Recent reports indicate that they have strong military backing, and are supported by underground Chinese and Thai groups (D. Walters, personal communication, May 2, 1994). Still a threat, Pol Pot has not been killed, and neither has his following, the Khmer Rouge.

Because of the United Nations' proposed peace plan in 1993, those living in the refugee camps at this time (several hundred thousand) were forced to repatriate back to their homelands. As an incentive to do so, a certain amount of land was promised to every returning family. Upon arrival in their homeland, these people were met with uncertainty, a wartorn country, and haunting memories. Homes were destroyed, friends and family were often missing or known to be dead, and there was much poverty. Even the land that was given each family often proved to be unmanageable due to active land mines covering the fields (personal interview, Marc Scalzi, May 6,1994), resulting in Cambodia currently 
having a higher number of amputees per capita than any other country in Asia (Chelminski, 1994, p. 107). So many adult Cambodians were killed under the Khmer Rouge regime that currently over $50 \%$ of the population of Cambodia is under the age of 16 (World Health Organization, 1992).

Though Cambodia has made notable accomplishments and has advanced a long way since the Khmer Rouge occupancy, the country today remains destitute. As one of the poorest countries in the world (Toole \& Waldman, 1993),

the legacy of the 1970's, followed by a decade of guerilla war and continued political and economic isolation have affected the Cambodian people immeasurably and limited the country's rehabilitation and development. The scars of the recent past remain in evidence, with thousands of amputees (many of them children and young people), ruined pagodas, schools, hospitals and factories, and a weak economic and social infrastructure. No less real are the scars that are unseen--the great dearth of skilled manpower and the trauma suffered by virtually the entire population. (Unicef, 1990, p.35)

\section{$\underline{\text { Rationale and Significance }}$}

The experiences of trauma resulted in serious psychological consequences. Repeated exposure to severe deprivation and traumatic events that occurred during and following the Khmer Rouge revolution in 1975 has, naturally, for many Cambodians resulted in the debilitating syndrome known as post-traumatic stress disorder (PTSD) described as symptoms following a psychologically traumatic event. As little has been published in this area specifically relating to Cambodians and post-traumatic stress disorder, the diagnostic parameters from the DSMIII-R used among Vietnam veterans are also used for this study.

It is hoped that this study will provide an exploration and overview of the manifestation and prevalence of PTSD among refugee and resettled Cambodians. From this, implications for alternative counseling approaches 
as well as a more in-depth understanding of PTSD and the kinds of trauma experienced will be understood.

Reasons for interest in examining the effects, manifestation, and prevalence of PTSD are both of an investigative and personal nature. Initially, the question of what such trauma will do to a person and how one can survive such odds is what launched an interest in this subject. What is the prevalence of PTSD among Cambodians living in the refugee camps? What are some experiences of post-traumatic stress which have been suffered? How are post-traumatic stress symptoms manifested? Considering the Southeast Asian culture, what are those who have resettled in America and experience PTSD doing to utilize mental health services? What is their attitude toward counseling? What are the implications for alternative counseling approaches? How can we better understand the nature of post-traumatic stress among Cambodians--victims of long-term trauma?

On a personal level, my interest in the welfare of the Cambodian people has been a part of life since 1979, when, as a child, I lived in Thailand with my parents, both of whom were intimately involved in humanitarian work within the Indochinese refugee camps located along the border of Cambodia and Thailand. I basically grew up with these camps, working and playing alongside the Cambodian children, becoming a part of the culture and customs of refugee life and Cambodian living. Refugee friends offered me an early exposure to the traumas undergone during and after Pol Pot's reign. Current studies in counseling have intensified my interest in post-traumatic stress disorder among Cambodians. 


\section{Statement of the Problem}

The purpose of this study was to examine the existence and evidence of post-traumatic stress disorder among refugee and resettled Cambodians with particular attention given to the cultural factors affecting its manifestation. Themes relating to PTSD offer a broader understanding of the disorder.

\section{Definition of PTSD}

The Journal of the American Psychiatric Association's Diagnostic and Statistical Manual of Mental Disorders, 3rd edition revised (DSM-III-R, 1987), states that post-traumatic stress disorder (PTSD) is a debilitating syndrome described as being "the development of characteristic symptoms following a psychologically traumatic event that is generally outside the range of usual human experience" (p. 247). According to the DSM-III-R, the symptoms of PTSD can be categorized into three major groups.

The first category includes those symptoms of reexperiencing the traumatic event. These symptoms may take the form of one of several psychic mechanisms: recurring nightmares, troublesome sleep patterns, depression, anxiety, flashbacks, panics, various physical symptoms, and feelings that they are suddenly back in the traumatic situation, to name just a few (Forman \& Havas, 1990).

The second category includes symptoms related to avoidance of stimuli associated with the traumatic event as evident in depression, withdrawal, isolating oneself, and becoming emotionally numb.

The third category of symptoms relates to increased arousal. These symptoms are exhibited by hyper-alertness, irritability, insomnia, excessive worrying, and over-aggressiveness. A diagnosis of PTSD is 
given in the case of at least one symptom being exhibited from the first category (re-experiencing the event), three symptoms from the second category (avoidance of stimuli), and at least two symptoms from the third category (increased arousal). The duration of these symptoms must have been present for at least six months following the incident.

Foreman and Havas (1990) conclude that "PTSD can be extremely disruptive to a person's physical and mental well-being, family life, social relationships, and employment status" (p. 173). Individuals could also have problems in concentrating and remembering because of their preoccupation with the trauma or event.

Acute PTSD would be diagnosed in the case of the onset of symptoms within 6 months of the trauma and/or the duration of symptoms are less than 6 months. Chronic PTSD occurs if the duration of symptoms lasts 6 months or more. Delayed acute PTSD is diagnosed if the onset of symptoms occurs at least 6 months after the trauma.

\section{Outline of the Thesis}

To better understand and explore the subject of post-traumatic stress disorder among Cambodians, the limited studies done on PTSD among Cambodian refugees and resettled people, along with studies and research done among Vietnam veterans, are assessed in chapter 2.

Chapter 3 describes the method used to explore the refugee camp situation. A sample survey of exhibited PTSD symptoms among Cambodians was carried out in the camps to assess the problem of PTSD. Chapter 3 also discusses methods used for the phenomenological interviews given to three subjects following resettlement. Follow-up interviews, conducted on these same three subjects 2 years later are also addressed in chapter 3 . 
Chapter 4 discusses the results and findings of the refugee camp survey, the interviews, given themes as well as implications for PTSD. Chapter 5 includes a discussion of PTSD as related to the found themes, and a discussion of cultural implications. Attitudes toward counseling are also assessed, and a summary and conclusion is given. 


\section{CHAPTER TWO}

\section{LITERATURE REVIEW}

In defining traumatized families and persons, Figley (1989) states that they "are those who are attempting to cope with an extraordinary stressor that has disrupted their normal life routine in unwanted ways" ( $p$. 5). Eth and Pynoos (1985) suggest that trauma occurs "when an individual is exposed to overwhelming events which cause feelings of helplessness in the face of intolerable danger, anxiety, and instinctual arousal" (p. 23). Herman (1992) reports that

people subjected to prolonged, repeated trauma develop an insidious, progressive form of post-traumatic stress disorder that invades and erodes the personality. While the victim of a single acute trauma may feel after the event that she is 'not herself', the victim of chronic trauma may feel herself to be changed irrevocably, or she may lose the sense that she has any self at all. (p. 86)

In her study of traumatized victims, Herman also states that "psychological trauma is an affliction of the powerless. At the moment of trauma, the victim is rendered helpless by overwhelming force," and "traumatic events overwhelm the ordinary systems of care that give people a sense of control, connection, and meaning" (p. 33).

Post-traumatic stress disorder has only recently been described. It was not recognized by the veterans association as a combat-related disorder until 1980 (Friedman, 1990). While there are some reports of the occurrence of PTSD among Nazi holocaust survivors, the majority of the information we have today is from studies done among the Vietnam veterans 
(Lancet, 1989). "In recent years, PTSD had frequently been associated with combat service in the Vietnam War, especially among those who saw significant amounts of combat" (Foy, Sipprelle, Rueger, \& Carrol, 1984, p. $80)$.

In a study of twins conducted by Goldberg, True, Eisen, and Henderson (1990), the prevalence of post-traumatic stress disorder among twins who served in Southeast Asia was $16.8 \%$ compared with 5.0\% of cotwins who did not serve in Southeast Asia. The three parameters from the DSM-III-R were used as diagnostic criteria in this study.

PTSD is not something only veterans can develop. It can be found in many populations, including sexually assaulted women, survivors of accidents and natural disasters, war, and any witnesses to violent acts (Sandrick, 1990). PTSD is now internationally accepted and established as a mental disorder that can occur to extreme lengths.

Some specific examples of incidents where high levels of PTSD were manifested among civilians include the effects of the fire that swept through King's Cross Underground Station in New York City on November 18, 1987. This incident severely affected those near the scene of trauma, those who merely witnessed the event, and those directly involved. While only 31 people were killed, and 7 people severely burned, over 600 came forward for psychiatric treatment, some so disturbed they were suicidal. In the case of the sinking ferry, psychiatrist John Gunn found $90 \%$ of those who survived the ordeal suffered from PTSD (Lancet, 1989).

From these cases, as well as the similarity of symptoms by Cambodians and Vietnam veterans, natural disaster survivors, and prisoners of war, a common denominator in the way the Cambodians respond 
to the trauma suffered in their homeland is suggested. There are definite parallels between those experiences of the Vietnam veterans and civilian cases, and the Indochinese. If a startling 90\% of civilians exhibit PTSD and are in need of psychological help from the short-term trauma of a ferry accident, surely the millions of Cambodians exposed to intense, prolonged trauma suffer from a similar diagnosis and are in need of similar services. Also, in one survey ("Centers for Disease Control," 1992), it is estimated that one or more symptoms of PTSD could affect approximately $50 \%$ of Vietnam veterans.

It can also be noted that PTSD symptoms are not always manifested immediately but may be triggered at some time after the trauma. In the case of the veterans, PTSD was prevalent as a result of their exposure to brutal casualties of war. These exposures occurred in relatively short periods of time. For the Indochinese, however, many have been victims to such brutality for more than a decade. Many Cambodian youth cannot recall what normal, peacetime life is like. The refugees who lived in the refugee camps had high levels of PTSD which could occur suddenly because the environment they lived in could trigger memories of the traumatic event.

The DSM-III-R (1987) states that "the disorder is apparently more severe and longer lasting when the stressor is of human design" (p. 247). While PTSD affects the person exposed to the trauma, there is also new evidence that it also affects the relatives of the victim, called "indirect victims.

Many of the surviving relatives, whether or not they witnessed the death, continue to suffer consequences of the tragedy long after its passing, becoming 'indirect victims' thus also suffering with PTSD. (Raymond, 1988, p. 3524) 
The symptoms resulting from the trauma experienced are very serious and can be debilitating. It generally affects the person's whole life, changing the way they view life. When something of this nature happens to the mind, it undergoes a dramatic, emotionally charged change. The analogy of how the pupil contracts when a bright light shines into someone's eye can illustrate how the mind constricts and shuts down in order to survive under pressures of a highly charged emotional event. Bonnie Green (1990), co-director of the Traumatic Stress Studies Center in Cincinnati, Ohio, illustrates the increasing seriousness of the psychological effects occurring from a trauma of human design by placing traumatic events on a continuum. "Natural disasters rank on the low end of the continuum" (p. 100). These would include hurricane victims, flood victims, those who have experienced their homes set on fire, and happenings where the victim has no control. These, apparently, cause less serious results. Green (1990) continues:

The most serious PTSD causing events would be disasters such as rape, crime and murder. When people deliberately hurt others, this is when professionals must deal with the largest psychological problems. Hence, the Cambodian holocaust has wreaked havoc and caused irreparable mind damage to the innumerous hordes of homeless, shifting refugees. (p. 100)

The fact that there is little documentation in regard to the mental health problem of PTSD in reference to refugees emphasizes the neglect of the issue (Goldfield, Mollica, Resavento, \& Karanone, 1988). Kelly Costigan (1989), however, addresses the growing issue of PTSD among refugees by saying that "the after-shocks of a disaster or an act of violence often leads to the debilitating syndrome known as PTSD" (p. 99). Jim Brooks (1989) also found this to be the case among Cambodian clients and said that "most of the people have nightmares about their family 
getting killed; they have them in the middle of the night and can't go to sleep. In the daytime, they sometimes suddenly feel a panic" (p. 8). Beverly McLeod (1985) adds that a study was done by psychiatrist Kinzie in which 13 Cambodians who suffered form PTSD were treated." Kinzie and his colleagues (1984) reported that his patients have "trouble sleeping and concentrating, often having nightmares and disturbing thoughts about their experiences in forced labor camps, are afraid of loud noises, and feeling attached to anyone" (p. 12).

In another recent study, the levels of trauma and psychiatric symptoms in a randomly chosen group of resettled Cambodians were ascertained. The findings concluded that a high proportion of resettled Cambodians who were not psychiatric patients did suffer from severe psychiatric symptoms. It was also found that there was a positive relationship between the amount of trauma they experienced and the severity of these symptoms (Carlson \& Rosser-Hogan, 1990).

The effects of long-term trauma and confinement on physical functional health and the mental health among Cambodians living in refugee camps were assessed in another study. The research design took place in the Site II refugee camp and involved a household survey of 993 adults. Conclusions included reports of extended trauma, poor health status, and depressive symptoms (Mollica et al., 1990).

\section{Resettlement Process}

Devastation, war, and turmoil have characterized the lives of post1975 Cambodians and have resulted in an influx of the resettlement to various asylum countries, one of which is the United States. In the past 14 years, over 700,000 Southeast Asian refugees have been accepted for 
resettlement (Mollica et al., 1990, p. 83). Upon arriving in the United States, the refugee is faced with numerous adjustment problems which only serve to compound past stressors and current symptoms of PTSD. The process of resettlement is emotionally, mentally, and physically demanding. What are the adjustment issues and obstacles faced by the repatriated refugee? Cultural difficulties, a language barrier, high unemployment rates, minimal finances, differences in the traditional value systems, religion, personal conduct and the threat to traditional family ties and loss of a familiar agricultural economy create some of the more significant adjustment factors (Kroll et al., 1989). One study found a positive relationship between trauma and poor physical health of resettled Cambodians (Uba \& Chung, 1991).

A typical case of resettlement might involve a Cambodian family struggling to make a living from a rural rice farm in the countryside of Cambodia. With the bombings and threats of war, they endure political strife and the Khmer Rouge atrocities. Following this, they flee, only to live for years in unsanitary refugee camps along the border of Thailand. The family waits in these camps of refuge, longing for acceptance to America. Like the thousands before them, they are accepted, and suddenly find themselves dropped into the middle of New York. Scared, with little knowledge of the language, the realities of life in America begin to $\operatorname{sink}$ in.

Several authors (Williams \& Westermeyer, 1986) argue that refugees endure greater stress than other immigrants because the refugee experience is involuntary. Refugees are pushed from their homeland, not pulled by the attractions of their destination. More gaps exist in research 
on refugees than on other types of immigrants.

One feeling shared by all refugees, which only serves to intensify PTSD symptoms, is the sense of loss caused by leaving behind homeland, friends, family, and personal belongings. "When other family members are unable to join the escape effort, or die in the process, the sense of loss for those left behind is overwhelming" (Muncy, 1988, p. 44), thereby compounding other stresses.

Lewis Nugenson, an immigration and resettlement counselor says,

In the eight years that I have been working with the Cambodians, I have come across many resettlement and adjustment problems that contribute to stress. A proper understanding of the English language is one of the problems. When the parents can not understand English, they have to rely on their children, and this upsets their whole system of family status. The child that understands English all of a sudden becomes very important. (personal communication, August 1990)

Grandparents may find their traditional authority questioned by their children and challenged by their grandchildren. They of ten feel useless, lonely and isolated. This role reversal has a profound effect on the family at large, only adding another stressor to compound PTSD effects from the past. There is generally little or no preparation for the challenge to the Cambodian's traditional value system by American society. How does one respond to a new culture that differs so drastically from one's own? "Having to adjust to Western culture and a whole new way of life, refugees of ten experience a sense of disillusionment, failure, and inadequacy as they try to make their way through a strange and frightening society without the support of their indigenous social systems or their extended families" (Bromely, 1987, p. 236). As one resettled refugee says, "We don't want to create more popcorn--those are little yellow kernels that, under pressure, turn white. We mustn't complete a genocide by forcing 
people to give up their identities" (Krich, 1990, p. 53). Of the many cultural differences, religion poses as perhaps the greatest challenge. Theravada Buddhism, the dominant religion in Indochina, is practiced by the majority of Cambodians. Buddhism is so much a part of the refugee's life, it is safe to say that it shapes their world view and culture. It is also a powerful force in their lives for dealing with trauma and psychological pain. Buddhism is seen as a solution for coping with post-traumatic stress. One of the beliefs in Buddhism recognizes that all people--no matter their race, age, or socio-economic status--will have problems and sufferings. Buddhism, however, is a source of hope and peace. The temples and pagodas, even those Buddhist temples located in large American cities, continue to act as a valuable refuge and a great source of comfort and mental peace of mind for those haunted by past trauma.

Included in the adjustment process and the trauma of suddenly realizing that you have lost your homeland and roots is culture shock. One authority (Robinson, $1980, \mathrm{p} .18$ ) claims that there are two periods of crisis for the refugee in culture shock.

The first is called simple culture shock, occurring anytime from 6 to 12 months after the refugee is settled. It is at this time that "he is suddenly faced with the realization of the total disparity between what he has known before and his current life" (Robinson, 1980, p. 23).

The next phase is about a year later. It is then that the refugee "comes to realize that he will never go back home and the total separation from native land, family, friends, and faith begins to weigh heavily upon him, to the point where he may feel that he will never cope with life" 
(Robinson, 1980, p. 23). The causes of depression (a major symptom of PTSD) among resettled Cambodians can be inferred from those stressors just presented.

Despite great odds, resettled Cambodians continue to struggle to make a life for themselves, to be rid of the title "a refugee" and to be free of the effects of experienced trauma. Faced by the many cultural differences and adjustment problems of resettlement, they struggle to find a balance between their native culture and that of the American society, while, at the same time, attempting to deal with PTSD.

\section{Summary of the Literature}

Psychological trauma can result in profound effects and the suffering of intense symptoms following a traumatic event. Information regarding PTSD among Vietnam veterans offers a basis for which to explore PTSD among refugee and resettled Cambodians. While investigation into the degree of PTSD among resettled Cambodians is still in its infancy, studies to date show alarming evidence of high rates of PTSD among those Cambodians who have resettled following the Khmer Rouge genocide. Trauma endured while living in Cambodia, the refugee camp experience, and resettlement stresses combine to present strong indication that, if not already the case, PTSD among Cambodians has reached a crisis state. 


\section{CHAPTER THREE}

\section{METHODOLOGY}

The purpose of this study was to explore the evidence for PTSD symptoms among refugee and resettled Cambodians in an effort to gain a better understanding of the mental health effects of long-term trauma. This was accomplished through informal surveys conducted in the refugee camp and by in-depth interviews conducted in the United States at two different times--2 years apart. Particular attention was given to the cultural factors affecting the manifestation of PTSD and cultural influences affecting help-seeking attitudes, particularly toward counseling as an option to dealing with PTSD.

\section{Type of Research}

There are two basic ways of approaching research: qualitatively and quantitatively. The traditional mode of research, the quantitative approach, describes phenomena through measures and statistics. Generally, it is well-defined, concrete, and consists of controlled events and conditions. The purpose of quantitative research includes verification with a singular reality manifold (Guba, 1978, p. 18). Patton (1980) describes quantitative measures as "succinct, parsimonious, and easily aggregated for analysis; quantitative data are systematic, standardized, and easily presented in a short space" (p. 28).

Qualitative research, however, seeks to understand the subject's 
"life world" and to make discoveries through explicit investigative methods. One approach of qualitative research involves "phenomenology, which attempts to study the human experience as it is lived" (Omery, 1982, p. 50). The phenomenological approach emphasizes the subject's experiences and point of view as key elements in discoveries and understandings to research questions put forth within the study. David Krathwohl (1993) clarifies this further by stating that "phenomenologists argue that it is an individual's [subject's] perceptions that count" ( $p$. $323)$.

Stemming from a humanistic philosophical base, the approach offers an expansionistic stance. Its value structure is pluralistic rather than singular, and "the naturalistic inquiry assumes a multiple reality--inquiry will diverge rather than converge" (Guba, 1981). The naturalistic inquiry, or phenomenological approach, assumes that the sum of the parts of the investigation is equal to, in the end, more than the sum of the initial parts, offering an expanded picture of what is studied. Therefore, reality is comprehended and enlarged because it is affected by many interrelated parts. It is by studying the detailed pieces that affect and influence the object of study (one such detail being the role of the researcher) that the entirety of information regarding the desired studied phenomena is obtained and comprehensively understood. In quantitative, conventional research, however, the phenomena is subdivided into pieces--"variables." It could be said in this case, then, that the whole is equal to the sum of the parts.

The inquiry process of the phenomenological approach includes unstructured interviews involving extensive, exhaustive descriptions, 
where subject and researcher explore together in the search for meaning. Analysis includes every piece of data obtained from and regarding the subject. Themes within the information are found, then clumped together into common categories in order to obtain a depiction of the general composition of the phenomena studied, which, in the case of this study, is post-traumatic stress disorder.

The approach could be considered an art (Tesch, 1990), and promotes a natural setting as compared to the traditional quantitative laboratory research setting (Guba, 1978, p. 18). Patton (1980) says, "The qualitative measures are longer, more detailed, and variable in content; analysis is difficult because responses are neither systematic nor standardized. Yet the open ended responses permit one to understand the world as seen by the respondents" (p. 28). It is the goal of the phenomenological researcher, through the quest to discern meaning, to be as objective as possible and to look at the phenomena through unbiased eyes, realizing that all elements affect one another.

This study employed the qualitative, phenomenological approach. The rationale for this approach suiting the nature of the study includes several reasons. First of all, because a gap exists in the literature regarding PTSD among resettled Cambodians, general information regarding what to look for, where to look for it and how to go about finding it, is lacking. Guba (1978) argues that there is a need for naturalistic inquiry as a preferred mode of interviewing when it is needed "to enlarge the arsenal of investigative strategies for dealing with emergent questions of interest" (p. 24).

Second, standardized questionnaire items for Cambodians related to 
a study of this nature, are unavailable. This is partly due to the lack of information on Cambodian PTSD. In addition, traditional questionnaires pertaining to PTSD lack the cultural sensitivity required for an accurate understanding of PTSD as it relates to Cambodian trauma victims. The qualitative, phenomenological approach, however, is suited to the Cambodian culture and was compatible with the purpose of this study. It allowed for a search of relevant themes associated with the subject in an exploration of post-traumatic stress disorder.

Third, socio-cultural factors make it difficult to follow a traditional quantitative approach or to use a standardized questionnaire. It was felt that this would not be congruous with traditional cultural values and would not be effective in eliciting the extensive range of experiences from the subject's perspective. Indochinese cultural customs of emotional modesty also contradict the intense, blunt, personal self-disclosure required by traditional quantitative scientific methods. One purpose of the study was to explore cultural manifestations of PTSD. The most efficient and culturally sensitive way to do this is to allow the subject to develop such themes through a qualitative means.

\section{Limitations of Methodology}

Although the qualitative approach to exploring and understanding PTSD among resettled Cambodians was the preferred modality, and the most effective one in this case, it does have some serious weaknesses and problems. Maanen (1983) mentions the most prominent by stating, "Qualitative data tend to overload the researcher badly at almost every point; the sheer range of phenomena to be observed, the recorded volume of notes, the time required for write-up, coding, and analysis can all 
become overwhelming" (p. 118). He continues, saying, "Collecting and analyzing the data is a highly labor-intensive operation, often generating much stress, even for top-quality research staff" (p. 118).

Finally, a limitation of the approach includes the fact that it is sometimes seen as not legitimate because of validity and reliability concerns (Tesch, 1990). The lack of concrete quantitative data make the qualitative study hard to replicate, and various distortions of the researcher, methodology, etc., are possible, contributing to the replicability of the design. The possibility of the researcher's biases, prejudices, incompetencies, gullibility, and corruptibility add to the lack of reliability and validity. However, it is difficult to establish safeguards against these threats.

\section{$\underline{\text { Subjects }}$}

Thailand Surveys

The methodology of this study involves three phases: the informal survey which took place in the Thailand refugee camps, the phenomenological survey interviews that took place in the United States, and the follow-up phenomenological interviews done 2 years following the initial U.S. interviews. The population of the first phase of this study, the Thailand survey of Cambodian refugees, included a sample of a mixed gender of adults over the age of 18 . The ages ranged from 22 to 56 , with a mean age of 34 . The subjects had all lived in the refugee camps for a period of at least 3 years.

Twenty-two people were selected by a systematic sampling plan from the Site II refugee camp that was divided into 22 sections of 500 people in each section. A total of 18 people were interviewed, 10 women and 8 
men. Of the 22 who were asked to be interviewed, 4 chose not to participate. The reasons given by each of these subjects were that "it was too much pain to think about the Pol Pot years." Upon arrival in the camps, families are assigned, at random, a section of the camp to live in based on availability. It was decided that a person from one family from the ninth hut of each section would be interviewed. (The traditional hut housed two to three families per hut.) The ninth hut was chosen because it was thought that this would be representative of the camp population. The first hut was not used because it often housed the section leader.

\section{Initial U.S. Phenomenological Interviews}

The second phase of the methodology involved in-depth phenomenological interviews with refugees who had resettled in the United States no later than 1-2 years prior to the interview. Three interviews were conducted with selected trauma victims. It was decided that only three interviews would be conducted due to time and financial constraints. A list of resettled Cambodian adults ages 18 years or older was requested from a refugee specialist who works extensively with Cambodians upon arrival to the United States. From this list, a male (Subject B) and female (Subject C) who had been resettled for at least two years, were selected by placing all the names of females in a hat, and drawing one name. This was also done for selecting subject B. A third subject (Subject A) was recommended by the refugee specialist and was selected based on the information that trauma had been experienced and that PTSD symptoms were evidenced by this subject. This subject was chosen because, of the three subjects interviewed, it was the researchers desire to have one subject of the three manifest PTSD symptoms. 
Subject A had also resettled in the United States 2 years prior to the interview. She lived with her older sister in an apartment in a small Californian town. Coming from a large family, Subject A and her sister were the only known survivors. In poor health at the time of the interview, Subject A was unable to work.

Subject B, a male, age 43 , lived in the ghettos of Chicago with a wife and three small children. Prior to 1975 , Subject B had been pursuing an advanced degree in history at a well-known Cambodian university. Subject B comes from a family of six members, all of whom, except his brother, died horrible deaths during Pol Pot's rule. At the time of the interview, Subject B was continuing to pursue an education in America, while working and taking care of his family. His family had resettled 2 years prior to Subject B being interviewed.

Subject $\mathrm{C}$ is a 30 -year-old, attractive female living in Phoenix, Arizona, with her mother and two girlfriends, all of whom escaped from Cambodia together. She had lived in the United States for 1.5 years prior to the interview. Subject $\mathrm{C}$ worked full time, and enjoyed the company of the local small Cambodian community.

Follow-up Phenomenological Interviews

The population and sample of the follow-up phenomenological interviews involved the identical three subjects interviewed in initial phenomenological interviews. As can be expected, in the 2-year period between interviews, some details changed such as location of residence, occupation, or health. No serious changes, however, such as death, brain injury, or not being able to locate the subjects took place. Subject A 
moved to Paris, France, while subjects $B$ and $C$ remained at their homes in Illinois and Arizona.

\section{$\underline{\text { Procedure }}$}

\section{Thailand Surveys}

During the month of January, 1991, the opportunity of visiting the refugee camps located along the Cambodian-Thai border was presented. Facilitated by refugee specialists and parents Jerry and Judy Aitken, the visit was made with the purpose of conducting the present study and gathering general information regarding post-traumatic stress disorder. Four of the seven camps--Site B, Khao-I-Dang, Phanat Ni Khone, and Site II--were visited. Approximately $31 / 2$ weeks were spent in these camps, at

which time interviews were conducted among the people in Site II camp, the largest of the seven camps at the time. Also, Site II camp was chosen because it is not a holding camp, meaning, those refugees already accepted for resettlement are not being held their temporarily, and it is not a longterm camp, meaning those living there had no hope for resettlement. Instead, it offered a nice mix of those who had been accepted for resettlement, those in waiting for resettlement, and those who had little chance of resettlement to an accepting country.

Permission to interview was obtained from the Thai Camp Commander of the Site II camp. By receiving a camp pass, permission to carry on interviews with volunteer personnel and the refugees was granted. A copy of one of the camp passes is included in Appendix A.

Because of the difficulty in understanding the foreign language, an interpreter highly skilled in Cambodian and English was provided for the interviews. This man, in his late 50s, worked for the United Nations High 
Commission for Refugees as a personal interpreter regarding private cases for resettlement. He had a reputation among the camp inhabitants as being trusted with confidential information.

The interviews lasted from 20 minutes to an hour and consisted of an open-ended question, followed by probes regarding the experiencing of specific PTSD symptoms. All interviews were tape-recorded, and consent forms were signed prior to participation.

The information regarding the sample choice was kept confidential to protect against potential interviewees being alerted. Upon arrival at the selected hut, a subject was chosen from the first family met inside the hut (usually the family who opened the door for the visit). The interviews were conducted in a place of the subject's choosing, which was usually in the privacy of his or her own hut. A total of 12.5 hours of recorded interviews was gathered.

Confidentiality was assured to the subjects, as no names or addresses were kept. Code numbers were given to the subjects (each one a letter and their section number of the camp) to ensure that interviewees were not repeated. The only requirements for each of the subjects were that they be a member of the ninth hut from the arbitrarily picked beginning in that particular section. This was in an effort to represent the normal population of the refugee camps.

The interview process was begun by an explanation to the subjects regarding the nature of the research, confidentiality, the purpose of the study, and their voluntary role as participants. The interview was initiated by asking open-ended questions along the following lines, in the presented order: (1) questions regarding the state of their general 
health, (2) the health of their family, and (3) trauma experienced following 1975. Clarification was asked for when necessary, and appropriate sensitivity was exercised regarding the emotional and painful nature of the subject of trauma. Active listening, reflective statements, gentle probes, and other techniques were employed to encourage the subjects to relate freely their own view of the situation and both past and present experiences. The interviews proved very emotional for the subjects as well as the researcher. Interviews were non-rushed, relaxed, and followed the lines of a casual conversation. It proved challenging to keep the interviews within a specified time limit, as the Asian hospitality is well known, and there were temptations to, when invited, join the family for a meal, talk extensively with the rest of the family, or admire crafts or other hobbies worked on in their spare time.

Interviews conducted were listened to at the close of each day, at which time notes were also re-read and PTSD symptoms were assessed, in the interest of obtaining information regarding the evidence and extent of the manifestation of PTSD symptoms by the sampled population. Only symptoms mentioned directly by the subjects were tallied and classified according to DSM-III-R categories as evidence of the existence of PTSD. Interviews were also conducted among mental-health personnel employed within the camps. These interviewees were asked what their opinion was in regard to PTSD, and if they feel it is manifested among the refugees. Following this, they were shown the interview survey results from this study, and asked to comment on these results. The results corroborate findings for PTSD. Those interviewed included the following: (1) the director of the traditional healing center in Khao-I-Dang camp, 
(2) the resident Swiss psychiatrist working with the United Nations High Commission for Refugees, (3) two Cambodian individuals recruited and trained as mental-health counselors, (4) one master's-level American counselor, and (5) a psychologist who has worked extensively with the Cambodians in various camps along the border. Data regarding numbers of Cambodians seeking help and reasons for eliciting help from the Traditional Medicine and Western Mental Health Clinics were also obtained from the psychologist in the camp. Finally, a tour of these facilities was conducted where efforts to combine traditional healing with Westernized concepts of counseling were in effect.

\section{Initial Phenomenological Interviews}

The second part of the methodology involved the phenomenological interviews conducted among the selected three subjects who had resettled in the United States. The method used to operationalize this part of the study included the interpretive, descriptive, phenomenological interview.

All interviews took place in the homes of the subjects. The interview began with a semi-focused question. Usually the question was along the lines of the health of the family, or how they were coping with resettlement. All of the subjects interviewed had been living in the United States for over a year, but not more than 2.5 years, and all spoke English fairly well. The phenomenological method used followed these steps:

1. Information regarding the nature of the research, confidentiality, the purpose of the study, and his or her voluntary role as participant is provided.

2. Tape recording of the interview begins.

3. A semi-focused question is asked in which the subject is 
encouraged to related his/her experiences freely. (See sample of interview questions included in Appendix B.)

4. Observations, notes of subject's behavior, and replies to questions are recorded during the course of the interview.

5. "Bracketing" is employed, which means getting rid of personal meanings and interpretations and entering into the subject's world (Tesch, 1990, p. 92), being conscious of personal, free suppositions and purposefully putting them out of mind.

6. Interview is conducted, probing when appropriate, engaging in active listening, reflection, and other person-centered interviewing techniques in an effort to gain more comprehensive information. Appropriate inquiries are made using questions related to PTSD as included in Appendix B .

7. Following the interview, observations and prominent topics are recorded.

8. Listen to tape and record transcripts another time.

The following steps involve the interpretive and descriptive analysis of the data as suggested by Tesch (1990):

9. Read, reread, and allow your thoughts to dwell on all the information you have obtained from the subject. Develop a sense of the subject's world.

10. Depict all meaning units in information obtained, and determine which pertain to research purpose and questions or look only at sections of interview that pertain to research purpose and questions and determine meaning units from this. Meaning units are described as "a part of the description whose phrases require each other to stand as a distinguishable 
moment" (Wertz, 1985, p. 165, cited in Tesch, 1990, p. 93). They are determined by noticing and identifying patterns of meaning and key sentences and phrases.

11. Meaning units are classified together into topics, by noticing commonalities between each one.

12. Topics are classified into themes by (a) listing topics, (b) determining related topics, (c) transcribing topics into categories, abbreviating category names and coding them for efficiency, and finally, (e) looking for commonalities, uniqueness, missing information, and contradictions.

13. Establish themes from categories after deciding on the most representational way to word themes.

14. Look for common themes and compare themes between interviews.

15. State themes pertaining to research questions.

16. Establish validity by discussing methods, analysis, conclusions, and diagnosis with authority.

17. Write thick descriptions. (See thick descriptions included in appendix C.)

As a final step in the initial phenomenological interviews conducted, the recommendations gathered from the diagnosis as suggested by a consulted authority (a clinical psychologist residing in Napa, California) were communicated to the subjects. The results from the interviews were also discussed with student advisors at the time of the interviews. If counseling was recommended, subjects were encouraged to pursue it. In communicating the recommendations, time and care were taken in the 
presentation of the information. This step was not taken, however, in conducting the follow-up interviews, as it was deemed unnecessary.

Each interview lasted over 3 hours (except follow-up interview with subject A), and was recorded on cassette tape. Following the semi-focused question, the subject was encouraged to relate his/her experience freely, although attempts were made to "lead" subjects toward topics dealing with interview questions. (See sample interview questions included in Appendix B.) Probes and questions relating to PTSD were interjected in an attempt to facilitate the process of reconstructing past memories and experiences as well as present feelings and PTSD symptoms experienced.

Limited guidance to the questions was given, as the subject basically had control of the interview. Immediately following the interview, I carefully transcribed the tapes, keeping in mind personal, free suppositions, then consciously putting them out of mind in an effort not to bias the results.

As the final step to the procedure, a final summary which is called a "thick description" of the interview was written. This provides a rough overview of the interview, and is descriptive of generally what was said during the interview. In the initial interviews, a summary of background experiences is included. These thick descriptions are not exhaustive of information obtained, but offer an overview of each subject's situation. They consist of one for each of the three subjects interviewed, and are included for further review in Appendix C.

Positive aspects I found regarding the interview process included the fact that a considerable amount of time was spent in the presence of the phenomena: interview time was between 2 to 5 hours. Also, detailed 
information was obtained regarding the context of the phenomena being studied. This proved beneficial in developing a comprehensive, expanded understanding of the issues of concern. The non-stressful, relaxed, home environment contributed to ease of self-disclosure and interviewing effectiveness.

\section{Follow-up Phenomenological Interviews}

Follow-up interviews complied with the same phenomenological format as initial phenomenological interviews. The follow-up interviews took place 2 years following initial phenomenological interviews. Information assessed that differed from that in initial interviews includes the following: (1) phenomena related to adjustment factors and resettlement issues, (2) the implementation of counseling recommendations following initial interviews was not included in the follow-up interviews, (3) their own attitudes towards counseling were assessed, and finally, (4) the status of PTSD symptomology as compared to initial interviews. Probe questions and desired target areas covered by questions are included in appendix $B$.

Interviews lasted approximately $21 / 2$ to 3 hours each. Confidentiality, the purpose of the study, and voluntary involvement were explained and when necessary, obtained, as was done in initial interviews. Thick descriptions on each subject interviewed were also done, however data concerning events leading up to the trauma were omitted as this is included in initial interview thick descriptions. These thick descriptions can be found in Appendix $\mathrm{C}$. 
Data Analysis of Initial and

Follow-up Phenomenological Interviews

Because of the need for a disciplined approach to the analysis of qualitative interview data, the following technique was adopted from Tesch (1990). First of all, phenomenological analysis is subjectively conducted. The researcher decides when to terminate data-analysis gathering, since the collecting of information could continue indefinitely. Analysis is also restricted not only to the interview, but involves all contact with and information gained from the subject. As seen in the following steps, analysis involves extensive comparing and contrasting, all the while remembering that the interviewer does affect in some way the process and information received.

Another important concept of phenomenological interviewing is the importance placed on reflection. Interviewing and analyzing data are not a scientific venture, but can be seen more along the lines of art. An eclectic approach to manipulating data is employed, and results are, in the end, expected to yield a greater picture of the whole.

The data analysis process is inductive and involves the following steps :

1. The data, meaning all information obtained from the subject, is broken down into meaning units. Meaning units can be described as sections of the text that represent a distinguishable moment or aspect of information. Meaning units can also be descriptive of a single idea.

2. Patterns, meaning similarities and commonalities, are noticed and identified from these meaning units.

3. Those determined patterns are then consolidated further into 
topics representative of the patterns.

4. The same process is repeated in each interview.

5. Redundant topics between interviews are then eliminated in order to arrive at the themes.

Themes are defined as prioritized statements relating to present research study issues. These statements are representative of:

1. Emphasized topics of the interviews

2. Issues relevant to and within the scope of the present study

3. Factors that are significant and additive to the understanding of the subject being studied, and as it relates to the whole picture of what is being studied.

Meaning units can further be described as descriptors of a single event, a single idea, or one piece of information gathered from the interviews. The following are examples: "I see many killings in my dreams"; "America is good to me"; "Sometimes I cry and cry and cannot stop"; "I try to forget about the sad memories."

\section{Summary of Methodology}

This study was conducted through a qualitative approach using a phenomenological interviewing method. The methodology of the study includes three phases: (1) the informal survey conducted in Thailand refugee camps, (2) the phenomenological interviews conducted among resettled Cambodian refugees upon immediately arriving in the U.S. and (3) follow-up interviews conducted among the same group as the initial U.S. phenomenological interviews. From these interviews, PTSD symptoms were assessed, and classified according to DSM-III-R categories. Also, themes were gathered from the interviews, contributing to an expanded 
understanding of the subjects' experiences and how they relate to the research questions and issues associated with PTSD. Finally, thick descriptions were written, offering an overview and further understanding of the subject. 


\section{CHAPTER FOUR}

\section{RESULTS}

The results of this study are comprised of three sections. The information gathered from the informal surveys conducted in the Thailand Cambodian refugee camps constitutes the first section. Along with the information from these interviews, the results of interviews with mental-health professionals within the refugee camps are presented. This provides a profile of PTSD symptomology among the Cambodians living in the refugee camps.

The second section includes results from the three phenomenological interviews conducted among Cambodians who had recently resettled within the United States. PTSD symptoms were assessed according to the fit of symptoms into the three categories of DSM-III-R diagnostic criteria. Data analysis is performed to arrive at topics which are then placed in categories from which themes are derived. Themes from each interview are then analyzed as they relate to PTSD. Following this, the themes from each interview are compared to the themes in the other two interviews. In this manner, repetitions and patterns across interviews are established.

The final section includes results from the follow-up interviews (follow-ups of initial phenomenological interviews are repeated 2 years later). Results from these interviews are acquired in a similar fashion to 
those of the initial interviews. New themes emerge, however, and key issues relating to post-traumatic stress disorder are explored during the interviews. These issues include attitudes toward counseling, adjustment to resettlement over the previous 2-year period, and coping behaviors in regard to PTSD symptoms.

\section{Results from Informal Survey in Thailand}

Of the 18 informal interviews conducted in Thailand, all persons interviewed fit the diagnostic criterion for PTSD of the DSM-II-R (1987) in that they had

experienced an event that is outside the range of usual human experience and that would be markedly distressing to almost anyone, e.g., serious threat to one's life or physical integrity; serious threat or harm to one's children, spouse, or other close relatives and friends; sudden destruction of one's home or community; or seeing another person who has recently been, or is being, seriously injured or killed as the result of an accident or physical violence. (p. 250)

In each interview given, all subjects had experienced the loss of at least one immediate family member. This is consistent with research findings (Rumbaut, 1985) showing that $80 \%$ of resettled Cambodians surveyed experienced the loss of, or were uncertain as to the fate of family members.

As Tables 1 and 2 illustrate, all 18 of those interviewed specifically mentioned symptoms that fell under the DSM-III-R categories constituting a possible diagnosis of post-traumatic stress disorder.

The results from these interviews, as seen in Tables 1 and 2 , clearly indicate that PTSD is evidenced among the refugee camp inhabitants, and is often severely manifested. The multiplicity of symptoms experienced was also alarming. Table 3 provides the percent of interviewees experiencing PTSD symptoms. As shown in the table, in "Reexpereincing the symptom," night-mares was reported most frequently. 
TABLE 1

SYMPTOMS REPORTED BY CAMBODIAN REFUGEES, SUBJECTS A TO I

\begin{tabular}{|c|c|c|c|c|c|c|c|c|c|}
\hline Symptoms & $\mathrm{A}$ & $\mathrm{B}$ & $\mathrm{C}$ & $\mathrm{D}$ & $\mathrm{E}$ & $\mathrm{F}$ & $\mathrm{G}$ & $\mathrm{H}$ & $\mathrm{I}$ \\
\hline \multicolumn{10}{|c|}{ Reexperiencing the Traumatic Event } \\
\hline Flashbacks & $\mathrm{X}$ & & & $\mathrm{x}$ & & $\mathrm{X}$ & & & $\mathrm{x}$ \\
\hline Nightmares & $\mathrm{X}$ & $\mathrm{X}$ & $\mathrm{X}$ & $\mathrm{X}$ & $\mathrm{X}$ & $\mathrm{X}$ & $\mathrm{X}$ & & $\mathrm{X}$ \\
\hline Panics & & $\mathrm{X}$ & $\mathrm{x}$ & $\mathrm{X}$ & & & $\mathrm{X}$ & $\mathrm{x}$ & $\mathrm{x}$ \\
\hline $\begin{array}{l}\text { Feeling you are back } \\
\text { at trauma }\end{array}$ & $\mathrm{X}$ & $\mathrm{X}$ & & & $\mathrm{X}$ & $\mathrm{X}$ & & $\mathrm{x}$ & \\
\hline \multicolumn{10}{|c|}{ Avoidance of Stimuli } \\
\hline Depression & $\mathrm{X}$ & $\mathrm{X}$ & $\mathrm{X}$ & & $\mathrm{X}$ & & & & $\mathrm{x}$ \\
\hline Anxiety & & $\mathrm{X}$ & $\mathrm{X}$ & & $\mathrm{X}$ & $\mathrm{X}$ & & $\mathrm{x}$ & \\
\hline Guilt & $\mathrm{X}$ & & & $\mathrm{X}$ & $\mathrm{X}$ & $\mathrm{x}$ & & $\mathrm{x}$ & \\
\hline Physical Symptoms & $\mathrm{X}$ & $\mathrm{X}$ & $\mathrm{X}$ & $\mathrm{X}$ & & $\mathrm{X}$ & $\mathrm{X}$ & $\mathrm{x}$ & $\mathrm{X}$ \\
\hline Emotional Numbness & $\mathrm{X}$ & & & & $\mathrm{X}$ & & & $\mathrm{x}$ & $\mathrm{X}$ \\
\hline Withdrawal & & $\mathrm{X}$ & $\mathrm{X}$ & $\mathrm{X}$ & & $\mathrm{X}$ & $\mathrm{x}$ & & \\
\hline Excessive Worrying & & $\mathrm{X}$ & $\mathrm{X}$ & $\mathrm{X}$ & & $\mathrm{X}$ & $\mathrm{x}$ & & \\
\hline \multicolumn{10}{|c|}{ Increased Arousal } \\
\hline $\begin{array}{l}\text { Relationship } \\
\text { Problems }\end{array}$ & $\mathrm{X}$ & $\mathrm{X}$ & $\mathrm{X}$ & & & & $\mathrm{X}$ & $\mathrm{x}$ & \\
\hline Hyper-alertness & & & & $\mathrm{x}$ & $\mathrm{X}$ & & & & $\mathrm{X}$ \\
\hline Insomnia & $\mathrm{X}$ & $\mathrm{X}$ & & $\mathrm{X}$ & $\mathrm{X}$ & $\mathrm{X}$ & $\mathrm{X}$ & $\mathrm{x}$ & \\
\hline Irritability & $\mathrm{X}$ & & & & $\mathrm{X}$ & & & $\mathrm{x}$ & $\mathrm{X}$ \\
\hline $\begin{array}{l}\text { Over- } \\
\text { Aggressiveness }\end{array}$ & & & $\mathrm{x}$ & & & $\mathrm{X}$ & & & \\
\hline
\end{tabular}


TABLE 2

SYMPTOMS REPORTED BY CAMBODIAN REFUGEES, SUBJECTS J TO R

\begin{tabular}{|c|c|c|c|c|c|c|c|c|c|}
\hline Symptoms & $\mathrm{J}$ & $\mathrm{K}$ & $\mathrm{L}$ & $\mathrm{M}$ & $\mathrm{N}$ & $\mathrm{O}$ & $\mathrm{P}$ & $Q$ & $\underline{\mathbf{R}}$ \\
\hline \multicolumn{10}{|c|}{ Reexperiencing the Traumatic Event } \\
\hline Flashbacks & $\mathrm{x}$ & & $\mathrm{x}$ & & $\mathrm{x}$ & & & $\mathrm{x}$ & \\
\hline Nightmares & $\mathrm{x}$ & $\mathrm{x}$ & $\mathrm{X}$ & $\mathrm{x}$ & $\mathrm{x}$ & & $\mathrm{x}$ & $\mathrm{x}$ & $\mathrm{X}$ \\
\hline Panics & $\mathrm{x}$ & & $\mathrm{X}$ & $\mathrm{X}$ & & $\mathrm{x}$ & & $\mathrm{x}$ & $\mathrm{X}$ \\
\hline $\begin{array}{l}\text { Feeling you are back } \\
\text { at trauma }\end{array}$ & & $\mathrm{X}$ & & $\mathrm{X}$ & & $\mathrm{x}$ & $\mathrm{x}$ & $\mathrm{x}$ & \\
\hline \multicolumn{10}{|c|}{ Avoidance of Stimuli } \\
\hline Depression & $\mathrm{x}$ & & & $\mathrm{x}$ & & $\mathrm{x}$ & & $\mathrm{x}$ & \\
\hline Anxiety & & $\mathrm{X}$ & & & $\mathrm{x}$ & $\mathrm{x}$ & $\mathrm{x}$ & $\mathrm{x}$ & \\
\hline Guilt & $\mathrm{X}$ & & $\mathrm{x}$ & & & $\mathrm{x}$ & & $\mathrm{x}$ & $\mathrm{X}$ \\
\hline Physical Symptoms & $\mathrm{x}$ & & $\mathrm{x}$ & $\mathrm{X}$ & $\mathrm{X}$ & $\mathrm{x}$ & $\mathrm{x}$ & & $\mathrm{X}$ \\
\hline Emotional Numbness & $\mathrm{X}$ & $\mathrm{X}$ & & & & $\mathrm{X}$ & $\mathrm{x}$ & $\mathrm{x}$ & \\
\hline Withdrawal & $\mathrm{X}$ & & & $\mathrm{X}$ & & $\mathrm{X}$ & & $\mathrm{x}$ & \\
\hline Excessive Worrying & & $\mathrm{X}$ & $\mathrm{X}$ & & $\mathrm{X}$ & & & & $\mathrm{X}$ \\
\hline \multicolumn{10}{|c|}{ Increased Arousal } \\
\hline $\begin{array}{c}\text { Relationship } \\
\text { Problems }\end{array}$ & & & & & & & & & $\mathrm{X}$ \\
\hline Hyperalertness & & $\mathrm{x}$ & & $\mathrm{X}$ & $\mathrm{X}$ & & & & $\mathrm{X}$ \\
\hline Insomnia & $\mathrm{x}$ & $\mathrm{x}$ & $\mathrm{x}$ & $\mathrm{X}$ & $\mathrm{x}$ & $\mathrm{X}$ & $\mathrm{X}$ & & \\
\hline Irritability & $\mathrm{X}$ & & $\mathrm{X}$ & $\mathrm{X}$ & $\mathrm{X}$ & $\mathrm{X}$ & & $\mathrm{X}$ & $\underline{X}$ \\
\hline $\begin{array}{l}\text { Over- } \\
\text { Aggressiveness }\end{array}$ & & & & $\mathrm{X}$ & $\mathrm{X}$ & & $\mathrm{X}$ & $\mathrm{X}$ & \\
\hline
\end{tabular}


TABLE 3

PERCENTAGE OF REPORTED SYMPTOMS BY CAMBODIAN REFUGEES

\begin{tabular}{||l|c|}
\hline Symptoms & \multicolumn{1}{|c|}{$\%(\mathrm{~N}=18)$} \\
\hline Nightmares & 89 \\
\hline Panics & 67 \\
\hline Feeling you are back at trauma & 56 \\
\hline Flashbacks & 44 \\
\hline \multicolumn{2}{|c|}{ Avoidance of Stimuli } \\
\hline Physical Symptoms & 83 \\
\hline Anxiety & 56 \\
\hline Guilt & 56 \\
\hline Depression & 50 \\
\hline Emotional Numbness & 50 \\
\hline Excessive Worrying & 50 \\
\hline Withdrawal & 50 \\
\hline & \\
\hline Insomnia & 78 \\
\hline Irritability & 61 \\
\hline Hyperalertness & 33 \\
\hline Over-Aggressiveness & 33 \\
\hline Relationship Problems & 33 \\
\hline
\end{tabular}


In the category "Avoidance of Stimuli," physical symptoms were reported with the highest frequency. And in the category "increased arousal", insomnia was reported most often.

As a measure taken to validate findings from the interviews, an interview pertaining to the PTSD results was conducted with the Site II resident camp psychiatrist. He confirmed these findings, stating, "I am not surprised by your findings. It has been estimated that over $90 \%$ of those in the camps suffer from PTSD as a result of what they've gone through" (personal communication, H. Svensberg, 1991).

When the discussion focused on exhibited signs of distress, most of the subjects who were interviewed proved to be very emotional. There was more hesitation on the part of the male subjects to discuss emotional symptoms than female clients. Because most Cambodians do not accept the concept of mental illness or psychology, questions relating to symptoms had to be clearly stated in a direct manner. Most questions were explicitly asked. Interviews became especially emotional when refugees were questioned about details of when the Khmer Rouge ruled from 1975 to 1979 .

One question asked in each interview was, "What do you do to deal with your . . . (whatever symptoms had been mentioned)." The answer given most frequently was, "Don't let myself think too much," or, similarly "Try to forget about it." Also, many subjects said that they had visited the traditional healing center in the camp for help. Interviews with camp mental-health professionals addressed this finding by stating that some of the people did come forward for help from the traditional medicine unit with complaints, most of which initially were physical in nature. The traditional healing center was seen as a more acceptable means of seeking help than 
the Westernized Mental Health Clinic.

A variety of remedies were offered by the Traditional Healing Center, some of which include herbs, saps, and other medicines, most of which were made in the unit by the psychiatric patients. The facility offered methods for the treatment of many symptoms of PTSD, such as headaches, flashbacks, insomnia, and other symptoms. For example, as a way to treat headaches, a dot could be burned onto the sufferer's forehead in an attempt to transfer the pain away from the location on the head that hurt.

Alongside the Traditional Healing Center was the Westernized Mental Health Clinic. These two centers worked together to provide for the mental health of the refugees. The less serious patients were sent to the traditional center, and the more serious ones to the Westernized clinic, where drugs were administered and counseling conducted.

The Cambodian and American mental-health counselors working in the centers also readily attested to the fact that PTSD was the number one mental health problem in the camps, as the people usually did not come forward for treatment from the westernized mental health center until the symptoms were very serious. They approved of the interviews conducted and commented on the lack of research currently done on the situation. Refugee mental-health specialist, Linda Engler, proposed that most, if not all of the people in the camps had PTSD, but that it wasn't something the people come forwards with, considering it something private, and their personal problem (personal communication, January, 1991).

The refugee camp's American psychologist working for the Red Cross was also interviewed. He had been working with the refugees for 
over 5 years. The interview included a variety of questions regarding the mental health of the refugees within the camps. In regard to the evidence and existence of PTSD, he corroborated Dr. Svensberg's report that PTSD is prevalent and a serious concern.

Many of the refugees live with the hope of getting to an accepting country like the U.S., and feel that once they arrive there, all their troubles and memories will disappear. They hold on for that one hope. When it is dashed, as it so often is (the countries turn them down) the depression and suicide rates sky-rocket. (personal communication, Robinson, 1991)

As an aspect of the interviews with the mental-health-specialist volunteers working with the United Nations High Commission for Refugees (UNHCR), treatment plans for various mental disorders were discussed. At that time the center had developed a program of intensive mental-health training of the Indochinese themselves, in order to aid in counseling their own people. Counseling was a new concept and seemed to be extremely needed and in demand. The need for this counseling is discussed by French (1990) who states that "the past and the present combine in the minds of camp residents and often produce powerful feelings of anger, frustration, depression, sometimes violence, and despair" (p. 30). This was evident from charts shown to the interviewer by these specialists, indicating the numbers of Cambodians seeking psychological assistance from the Westernized and Traditional healing centers in the past month. Of the 248 people seeking help during the month of November, over three quarters were diagnosed as suffering from PTSD. 
Initial and Follow-up Phenomenological

$\underline{\text { Interviews }}$

Based on the analytical approach presented in chapter 3 , the following are some of the patterns that were elicited from the meaning units in the interviews: feelings--both negative and positive, symptoms related to PTSD; family--both past and present; friends--both past and present, as well as those in refugee camps and those who managed to escape with subjects; relationships to people in present as well as relationships in the past; physical health; mental health; memories of past hard times and good times; the mind and pain and happiness; adjustment to life in the U.S.; difficulties; dreams met and lost; counseling as an option; attitudes toward America; attitudes toward current Cambodia; attitudes toward coping, forgetting Pol Pot; childhood, work, school, future, past goals, religion, belief, trust, shame, guilt, methods of coping, refugee-camp experiences, and hope.

Redundancies in the above topics were eliminated, and remaining topics were placed in the following categories as established themes:

(1) resettlement/adjustment, (2) symptoms, (3) spiritual issues,

family, (5) trust, and (6) the future. Table 4 illustrates the relationship between the meaning units and the arrived-at themes.

From these themes arrived at from the interviews and information gathered, the following statements relating to PTSD can be made in relation to each theme:

1. The Cambodian's adjustment to resettlement continues to be a challenging, on-going process filled with negatives and challenges, blessings and hopes. It serves to compound symptoms of PTSD. 
TABLE 4

\section{MEANING UNITS AND THEMES \\ PRESENTED FROM PHENOMENOLOGICAL INTERVIEWS}

\begin{tabular}{|c|c|}
\hline $\begin{array}{l}\text { Meaning } \\
\text { units }\end{array}$ & $\begin{array}{l}\text { Theme 1: Resettlement and Adjustment } \\
\text { "The english language is very difficult for my mother to } \\
\text { learn." } \\
\text { "I have a problem to learn english." } \\
\text { "My children can learn to speck english very quickly." } \\
\text { "America is good to me, but Cambodia is my home." } \\
\text { "My sponsor is very good to me, but I miss Cambodia." } \\
\text { "I like American food." } \\
\text { "My grandma have a difficult time getting used to America." } \\
\text { "I prepare myself to live in this country when I live in the } \\
\text { refugee camp." } \\
\text { "I go to school to learn for my future." } \\
\text { "I hate the cold weather." } \\
\text { "I want to go back to Cambodia to visit there." } \\
\text { "America is good to me." } \\
\text { "I like the American way, but sometime I don't know which } \\
\text { one to choose." }\end{array}$ \\
\hline $\begin{array}{l}\text { Meaning } \\
\text { units }\end{array}$ & $\begin{array}{l}\text { Theme 2: Symptoms } \\
\text { "I feel anxious many times." } \\
\text { "I have a big sadness." } \\
\text { "I feel guilt over my escape without my sister." } \\
\text { "I experience many bad dream--every three times a week." } \\
\text { "I experience big pain in all of my body." } \\
\text { "my hair hurts." } \\
\text { "my mind wanders." } \\
\text { "I cry so many times." } \\
\text { "I cannot stand to be with my sister for a long time." } \\
\text { "I see the killing in my dream." } \\
\text { "When I hear someone talking, sometimes I can her my } \\
\text { mother, but it is not my mother." } \\
\text { "Many times my wife will cry when she sleeps at night." } \\
\text { "I cannot remember one year." } \\
\text { "I have many bad dreams." } \\
\text { "I have deep pain in the side of my head." } \\
\text { "Many times I become angry at my wife." } \\
\text { "Sometimes I feel like to die." } \\
\text { "I hate the night-time." } \\
\text { "The mind, my mind, is thinking too much." } \\
\text { "Sometimes my mind sees the darkness." } \\
\text { "I am trving to forget." }\end{array}$ \\
\hline
\end{tabular}


Table 4--Continued.

\begin{tabular}{|c|c|}
\hline $\begin{array}{l}\text { Meaning } \\
\text { units }\end{array}$ & $\begin{array}{l}\text { Theme 3: Spiritual Issues } \\
\text { "Many people go to the temple to have peace." } \\
\text { "I worship God to get peace." } \\
\text { "In Cambodia the villages are peaceful." } \\
\text { "Everyone must suffer, then they will have peace in another } \\
\text { life." } \\
\text { "I love Cambodia because there it is so quiet and peaceful." } \\
\text { "The monk gives me peace." } \\
\text { "Everyone needs to feel harmony with their self." }\end{array}$ \\
\hline $\begin{array}{l}\text { Meaning } \\
\text { units }\end{array}$ & $\begin{array}{l}\text { Theme } 4 \text { : Trust } \\
\text { "Sometimes I cannot trust the other people." } \\
\text { "I will not get away from my mom's bones." } \\
\text { "I do not have a belief in the government system." } \\
\text { "There are many dishonest people in the world." } \\
\text { "I think Cambodia is not a good place, there is too much } \\
\text { killing." } \\
\text { "My parents were the honest people." } \\
\text { "People change after the war, in Cambodia." } \\
\text { "I have suspicion of most people, now." }\end{array}$ \\
\hline $\begin{array}{l}\text { Meaning } \\
\text { units }\end{array}$ & $\begin{array}{l}\text { Theme } 5 \text { : Family } \\
\text { "I miss my mother so much." } \\
\text { "All my dream is about my family who die." } \\
\text { "I can only talk to my wife." } \\
\text { "The worse thing about Pol Pot time is what he did to the } \\
\text { family. I will never forgive this cruelness." } \\
\text { "I never saw my father again." } \\
\text { "I have childhood memories of my parents. This always } \\
\text { makes me cry to think about it." }\end{array}$ \\
\hline $\begin{array}{l}\text { Meaning } \\
\text { units }\end{array}$ & $\begin{array}{l}\text { Theme 6: The Future } \\
\text { "I feel concern about the future." } \\
\text { "I want for my children to have a good future." } \\
\text { "I never gave up because I think maybe I will find happiness } \\
\text { someday." } \\
\text { "I have a plan for my life." } \\
\text { "I dream of the future." } \\
\text { "Maybe in the future I will forget." } \\
\text { "I have many dreams about my future. I want to ...." }\end{array}$ \\
\hline
\end{tabular}


2. A wide variety of symptoms of PTSD exist and are exhibited to varying degrees by resettled Cambodians.

3. Family in all respects is of utmost importance and is a major source of support and strength in coping with PTSD symptomology .

4. A belief in a higher power envelops the life of the Cambodian, influencing in multiple ways, guiding, aiding, offering peace and hope as a valuable tool in coping with PTSD.

5. Issues of trust and mistrust confront resettled Cambodians as a by-product of past trauma and war experiences. These issues also have repercussions towards engaging in counseling as a healing option.

6. The future is extremely important and is used as a coping mechanism to deal with PTSD symptoms. It is attached to resettlement issues, and issues surrounds the family.

Because theme \#2, symptoms of post-traumatic stress disorder, was the dominant thrust of the present study, this theme was further looked at and analyzed according to each individual interview. Symptoms were assessed and placed into the DSM-III-R categories to indicate evidence of PTSD. From these tables on each subject, a quick over-view of symptoms experienced is also shown.

\section{Initial Interview Results}

None of the three people interviewed had been diagnosed as suffering from PTSD. However, following the interviews, symptoms reported supported a diagnosis for each subject as suffering from PTSD. Table 4 provides this diagnosis of PTSD for the first subject interviewed: Miss A; minor symptoms were also mentioned by Miss A, although the table presents only the most chronic of these symptoms. The interview proved 
long and exhausting. Miss A was somewhat reluctant to talk, but after some time passed, she opened up considerably. It was evident that she appreciated the company.

Miss A did seek psychological help from a psychologist. She experienced the most severe symptoms of those interviewed, and, at the time of the initial interview, was in great pain. Miss A stated that she had gone to several medical doctors, and was repeatedly told that she was healthy and there was no physical basis for her pain. She had also gone to two psychologists who, Miss A states, did not inquire into her past, but diagnosed her as depressed and placed her on anti-depressant medication which she claimed did not help. Following this, Miss A stated she had begun to "feel suicidal." Table 5 is included for review of the symptoms reported by Miss A as they fit the DSM-III-R diagnostic criteria of PTSD. These reported symptoms were obtained from information given during the interviews. The interview for Miss $A$ is written up in a thick description \#1 as found in Appendix $\mathrm{C}$, Case One. This thick description offers an overview of the symptoms mentioned in Table 5 and other background information obtained from Miss A. The thick descriptions also give information from which the themes were obtained. 
TABLE 5

DSM-III-R CLASSIFIED SYMPTOMS REPORTED BY SUBJECT A DURING THE INITIAL PHENOMENOLOGICAL INTERVIEW

\begin{tabular}{|c|c|c|}
\hline $\begin{array}{l}\text { Diagnostic } \\
\text { Parameters }\end{array}$ & $\begin{array}{l}\text { Occurring } \\
\text { Symptoms }\end{array}$ & Examples \\
\hline \multirow[b]{2}{*}{$\begin{array}{l}\text { Reexperiencing } \\
\text { the } \\
\text { Traumatic } \\
\text { Event }\end{array}$} & Flashbacks & $\begin{array}{l}\text { Minor daily happenings trigger } \\
\text { flashbacks. When door slams, } \\
\text { she screams and falls to the } \\
\text { floor. Hearing her sister's voice } \\
\text { often also triggers flashbacks. }\end{array}$ \\
\hline & Nightmares & $\begin{array}{l}\text { Subject is frightened to go to } \\
\text { sleep from fear of the continual } \\
\text { nightmares she suffers from. "I } \\
\text { am always running from the } \\
\text { killing in my dream. I always } \\
\text { dream. I cannot stop the } \\
\text { killing. I see my mom being } \\
\text { killed." }\end{array}$ \\
\hline \multirow{3}{*}{$\begin{array}{l}\text { Avoidance of } \\
\text { Stimuli }\end{array}$} & Anxiety/Guilt & $\begin{array}{l}\text { Subject cries often and blames } \\
\text { herself for her mother's and } \\
\text { sister's death. She feels she } \\
\text { doesn't deserve to be living. } \\
\text { She also prays and wonders } \\
\text { why God doesn't help. }\end{array}$ \\
\hline & $\begin{array}{l}\text { Emotional } \\
\text { Numbness }\end{array}$ & $\begin{array}{l}\text { Subject's symptoms are } \\
\text { debilitating. She lies in bed all } \\
\text { day, only able to do minor jobs } \\
\text { around the house. She } \\
\text { constantly battles to keep } \\
\text { control of her mind. "My mind } \\
\text { wanders. I feel dead inside." }\end{array}$ \\
\hline & $\begin{array}{l}\text { Physical } \\
\text { Symptoms }\end{array}$ & $\begin{array}{l}\text { "My hair hurts, my finger nails } \\
\text { hurt. I feel terrible pain in my } \\
\text { back and legs and at times I } \\
\text { cannot move because of pain." }\end{array}$ \\
\hline Increased Arousal & $\begin{array}{l}\text { Interpersonal } \\
\text { Relationship } \\
\text { Problems }\end{array}$ & $\begin{array}{l}\text { "I cannot stand to be with my } \\
\text { sister for long. She cannot } \\
\text { understand my pain. She did } \\
\text { not see what I saw in } \\
\text { Cambodia." }\end{array}$ \\
\hline
\end{tabular}


The second subject, Mr. B, was initially thought not to suffer from serve PTSD as he appeared to be functioning well, and reported prior to the interview that he was doing "great." The interview proved otherwise, however, and Mr. B reported multiple symptoms that were causing much trouble for him in various aspects of his life. Mr. B stated that he felt the symptoms relayed during the course of the interview were of a very personal nature, and expressed concern over having "burdened" the interviewer with such details and troubles of a personal nature. The symptoms Mr. B suffered were affecting multiple aspects of his life. Discussing both physical and emotional pain was very difficult for Mr. B. Table 4 provides a breakdown of symptoms $\mathrm{Mr}$. B reported experiencing for more than 6 months prior to the interview. The thick description \#2, in Appendix C, describes in fuller detail Mr. B's past experiences and background information that have brought about the symptoms suffered by Mr. B described in Table 6 .

Miss $\mathrm{C}$ also related extensive trauma she had experienced while living in Cambodia. The interview proved very emotional and lengthy. Many symptoms were evidenced and directly relayed by Miss C. She also talked extensively about life in America, resettlement, and coping. Nightmares were a repeated concern for Miss C. She states that they have persistently troubled her for years. Table 7 provides a description of symptoms reported by Miss $\mathrm{C}$ that had been experienced for over 6 months prior to the interview. In fact, Miss $\mathrm{C}$ states she has had these symptoms since leaving Cambodia. Background experiences which precipitated the symptoms are described in the Thick Description \#3, Case Three. Also, 
TABLE 6

DSM-III-R CLASSIFIED SYMPTOMS REPORTED BY SUBJECT B DURING THE INITIAL PHENOMENOLOGICAL INTERVIEW

\begin{tabular}{|c|c|c|}
\hline $\begin{array}{l}\text { Diagnostic } \\
\text { Parameters }\end{array}$ & $\begin{array}{l}\text { Occurring } \\
\text { Symptoms }\end{array}$ & Examples \\
\hline \multirow{2}{*}{$\begin{array}{l}\text { Reexperiencing } \\
\text { the } \\
\text { Traumatic } \\
\text { Event }\end{array}$} & Flashbacks & $\begin{array}{l}\text { Subject gets them } \\
\text { approximately once a month. } \\
\text { He admits that faces and } \\
\text { voices trigger painful } \\
\text { memories. "I try not to } \\
\text { remember. I block out past } \\
\text { memories." }\end{array}$ \\
\hline & Nightmares & $\begin{array}{l}\text { Subject has many terrible } \\
\text { dreams, and they are always } \\
\text { of the Khmer Rouge. He tells } \\
\text { of how these dreams haunt } \\
\text { him. Often he is afraid to fall } \\
\text { asleep at night. }\end{array}$ \\
\hline \multirow{3}{*}{$\begin{array}{l}\text { Avoidance of } \\
\text { Stimuli }\end{array}$} & Anxiety/Guilt & $\begin{array}{l}\text { Subject feels that he is partly } \\
\text { to blame for death of his } \\
\text { father, brothers, and child. } \\
\text { He relives scenes of murder } \\
\text { constantly in his mind. }\end{array}$ \\
\hline & $\begin{array}{l}\text { Emotional } \\
\text { Numbness }\end{array}$ & $\begin{array}{l}\text { Subject says that periods of } \\
\text { time can go by and he doesn't } \\
\text { realize it. This happens when } \\
\text { he remembers trauma. }\end{array}$ \\
\hline & $\begin{array}{l}\text { Physical } \\
\text { Symptoms }\end{array}$ & $\begin{array}{l}\text { Subject has constant sniffle } \\
\text { that he did not have before } \\
\text { experienced traumas. } \\
\text { Physicians can find no } \\
\text { physical cause for this. } \\
\text { Subject also has severe } \\
\text { headaches constantly. }\end{array}$ \\
\hline Increased Arousal & $\begin{array}{l}\text { Interpersonal } \\
\text { Relationship } \\
\text { Problems }\end{array}$ & $\begin{array}{l}\text { Subject has difficulty with } \\
\text { family members, of ten getting } \\
\text { into fights or arguments with } \\
\text { his wife. He states he finds he } \\
\text { is often irritable with his } \\
\text { children, as well. Subject has } \\
\text { difficuity relating to wife and } \\
\text { children. }\end{array}$ \\
\hline
\end{tabular}


TABLE 7

DSM-III-R CLASSIFIED SYMPTOMS REPORTED BY SUBJECT C DURING THE INITIAL PHENOMENOLOGICAL INTERVIEW

\begin{tabular}{l|ll}
\hline $\begin{array}{l}\text { Diagnostic } \\
\text { Parameters }\end{array}$ & $\begin{array}{l}\text { Occurring } \\
\text { Symptoms }\end{array}$ & Examples \\
\hline \multirow{2}{*}{$\begin{array}{l}\text { Reexperiencing } \begin{array}{l}\text { Traumatic } \\
\text { Event }\end{array} \\
\text { Nightmares }\end{array}$} & $\begin{array}{l}\text { She sees her sisters being } \\
\text { killed and her family shot in the } \\
\text { forest or caught in the camp } \\
\text { from their hiding place. She } \\
\text { wakes up screaming. }\end{array}$ \\
\cline { 2 - 3 } & $\begin{array}{l}\text { Concentration } \\
\text { Difficulties }\end{array}$ & $\begin{array}{l}\text { She thinks often of her friends } \\
\text { and life in Cambodia. She does } \\
\text { poorly in school. }\end{array}$ \\
\hline \multirow{4}{*}{$\begin{array}{l}\text { Avoidance of } \\
\text { Stimuli }\end{array}$} & Insomnia & $\begin{array}{l}\text { She is afraid of sleeping } \\
\text { because the dark brings back } \\
\text { bad memories. She must sleep } \\
\text { very late. }\end{array}$ \\
\cline { 2 - 3 } & Depression & $\begin{array}{l}\text { She told me how she hates her } \\
\text { life in Site 2 Camp. She feels } \\
\text { like an animal in a cage. }\end{array}$ \\
\cline { 2 - 3 } & Overagressivenes & $\begin{array}{l}\text { She has an unusually strong } \\
\text { temper. She takes her feelings } \\
\text { out on her family. }\end{array}$ \\
\cline { 2 - 3 } Increased Arousal & She cries uncontrollably. She \\
& Symptoms & $\begin{array}{l}\text { Sheels weak after remembering } \\
\text { her flashbacks. }\end{array}$ \\
\hline
\end{tabular}


the symptoms outlined in Table 7 are obtained from Ms. C's interview as relayed in this Thick Description, Case Three.

\section{Follow-up Interview Results}

Miss A demonstrated many of the same symptoms as she had in the initial interview 2 years earlier. The symptoms did not appear to have increased, but rather had leveled off. Nightmares continued as the dominant symptom. Miss A felt that her current active involvement in therapy was helping her. She followed through with counseling as was suggested following the interview conducted 2 years previously. Table 8 gives an account of symptoms constituting a diagnosis of PTSD as reported by Miss A. A Thick Description (\#4) of the follow-up interview for Miss A, (Case One) is included in Appendix C, and describes how Miss A is currently doing--2 years following the initial interview conducted.

Mr. B also reported similar symptoms to those discovered 2 years earlier. His symptoms can be found in Table 7. He still fits the diagnosis as suffering from PTSD; however, though he feels he is doing better in dealing with things on one level. Nevertheless, returning for a visit to Cambodia recently has brought a new recurrence of memories, but not an increase in nightmares or other painful symptoms. In fact, Mr. B. feels that perhaps his visit has helped him to accept and to understand so as to "give better peace about things." The symptoms experienced by Mr. B are as outlined in Table 9 are further explained in Appendix C, Thick Description \#5. 
TABLE 8

DSM-III-R CLASSIFIED SYMPTOMS REPORTED BY SUBJECT A DURING THE FOLLOW-UP PHENOMENOLOGICAL INTERVIEW

\begin{tabular}{l|ll}
\hline $\begin{array}{l}\text { Diagnostic } \\
\text { Parameters }\end{array}$ & $\begin{array}{l}\text { Occurring } \\
\text { Symptoms }\end{array}$ & Examples \\
\hline $\begin{array}{l}\text { Reexperiencing } \\
\text { Eve Traumatic }\end{array}$ & Flashbacks & $\begin{array}{l}\text { "So many times I can see my family } \\
\text { in my mind. I can see my mother } \\
\text { and my sister. It is so painful." }\end{array}$ \\
\cline { 2 - 3 } & Nightmares & $\begin{array}{l}\text { "I always have the bad dream. I } \\
\text { think that therapy helps, but I still } \\
\text { have the bad dream." }\end{array}$ \\
\hline \multirow{4}{*}{$\begin{array}{l}\text { Avoidance of } \\
\text { Stimuli }\end{array}$} & Anxiety/Guilt & $\begin{array}{l}\text { "I don't know why I have to live, or } \\
\text { why I still have these dreams when } \\
\text { I do everything good to get rid of } \\
\text { it." }\end{array}$ \\
\cline { 2 - 3 } & $\begin{array}{l}\text { Emotional } \\
\text { Numbness }\end{array}$ & $\begin{array}{l}\text { "Sometimes I can't feel anything on } \\
\text { my body." }\end{array}$ \\
\cline { 2 - 3 } & $\begin{array}{l}\text { Physical } \\
\text { Symptoms }\end{array}$ & $\begin{array}{l}\text { "I still have headache, and pain in } \\
\text { my stomach. It is difficult for me } \\
\text { to eat. My pain before when you } \\
\text { talk to me is gone, but now it still } \\
\text { comes to different parts of my body } \\
\text { when I have a bad dream." }\end{array}$ \\
\hline Increased & $\begin{array}{l}\text { "I fight with my sister all the time. } \\
\text { I don't think that she understands } \\
\text { my suffering." }\end{array}$ \\
\hline
\end{tabular}


TABLE 9

DSM-III-R CLASSIFIED SYMPTOMS REPORTED BY SUBJECT B DURING THE FOLLOW-UP PHENOMENOLOGICAL INTERVIEW

\begin{tabular}{|c|c|c|}
\hline $\begin{array}{l}\text { Diagnostic } \\
\text { Parameters }\end{array}$ & $\begin{array}{l}\text { Occurring } \\
\text { Symptoms }\end{array}$ & Examples \\
\hline \multirow{2}{*}{$\begin{array}{l}\text { Reexperiencing } \\
\text { the Traumatic } \\
\text { Event }\end{array}$} & Flashbacks & $\begin{array}{l}\text { "I have had this problem ever since } \\
\text { I arrive in America. I see my } \\
\text { family in the faces of my friends, } \\
\text { and it frightens me when this kind } \\
\text { of thing happen." }\end{array}$ \\
\hline & Nightmares & $\begin{array}{l}\text { "My wife and I always have the } \\
\text { dream. The dreams never stop, } \\
\text { and we can never have peace from } \\
\text { these dreams." }\end{array}$ \\
\hline \multirow[t]{3}{*}{$\begin{array}{l}\text { Avoidance of } \\
\text { Stimuli }\end{array}$} & Anxiety/Guilt & $\begin{array}{l}\text { "I don't know why I will live and } \\
\text { not my brother who is more good } \\
\text { than I am." }\end{array}$ \\
\hline & $\begin{array}{l}\text { Emotional } \\
\text { Numbness }\end{array}$ & $\begin{array}{l}\text { "I do not remember a lot about the } \\
\text { killing or the time during the Pol } \\
\text { Pot reign. When I returned to visit } \\
\text { Cambodia, I remembered some } \\
\text { painful thing that I had forgotten } \\
\text { before." }\end{array}$ \\
\hline & $\begin{array}{l}\text { Physical } \\
\text { Symptoms }\end{array}$ & $\begin{array}{l}\text { "I still have soreness in my muscle } \\
\text { for no reason, and I have this } \\
\text { sniffle that the doctor does not } \\
\text { know what is the matter. I already } \\
\text { get used to it. It becomes worse } \\
\text { when I have the memories of my } \\
\text { country, and for no reason during } \\
\text { some times of the month." }\end{array}$ \\
\hline $\begin{array}{l}\text { Increased } \\
\text { Arousal }\end{array}$ & $\begin{array}{l}\text { Interpersonal } \\
\text { Relationship } \\
\text { Problems }\end{array}$ & $\begin{array}{l}\text { "I still have the problem with my } \\
\text { family. It never got better for two } \\
\text { years, now." }\end{array}$ \\
\hline
\end{tabular}


Miss $C$ reported the symptoms shown in Table 10. She expressed much pain, and interestingly, due to the development of new memories coming to consciousness, her symptoms appeared to escalate over the ensuing 2 years. These symptoms, as well as information regarding how Miss $\mathrm{C}$ is currently coping, along with general life information on Miss $\mathrm{C}$, is included in the Thick Description \#6, in Appendix C. Her specific symptoms as they fall into DSM-III-R categories are summarized in Table 10 .

\section{Conclusions}

A survey conducted in the Site II refugee camp indicates an alarming rate of PTSD as experienced among Cambodian refugees. Interviews with refugee camp mental-health personnel substantiate these findings. Information obtained during phenomenological surveys among selected resettled Cambodians, as well as follow-up interviews show evidence of post-trauma symptoms among those who have come to the U.S. to resettle, as well. Themes and information regarding the trauma experienced and currently being suffered from offer a holistic understanding of the post-trauma experience of the resettled Cambodian. As symptoms of PTSD is the thrust of the current study, those symptoms reported by each subject interviewed are illustrated in Tables 4 through 9 as indicative of the DSM-III-R diagnostic criteria each symptom fits.

Information gathered from the phenomenological interviews is written up in the Thick Descriptions \#1-6, and provides an overview of each interview, offering knowledge and understanding pertaining to the symptoms and manifestation of trauma and PTSD, the utilization of 
TABLE 10

DSM-III-R CLASSIFIED SYMPTOMS REPORTED BY SUBJECT C DURING THE FOLLOW-UP PHENOMENOLOGICAL INTERVIEW

\begin{tabular}{|c|c|c|}
\hline $\begin{array}{l}\text { Diagnostic } \\
\text { Parameters } \\
\end{array}$ & $\begin{array}{l}\text { Occurring } \\
\text { Symptoms }\end{array}$ & Examples \\
\hline \multirow{2}{*}{$\begin{array}{l}\text { Reexperiencing } \\
\text { the Traumatic } \\
\text { Event }\end{array}$} & Flashbacks & $\begin{array}{l}\text { I always have the flashback of the } \\
\text { memory of Cambodia. I don't have } \\
\text { any medicine that can stop this } \\
\text { from happening. }\end{array}$ \\
\hline & Nightmares & $\begin{array}{l}\text { "Dreams are my biggest problem, } \\
\text { because I cannot control them. I } \\
\text { dream about my grandmother and } \\
\text { my father dying." }\end{array}$ \\
\hline \multirow{3}{*}{$\begin{array}{l}\text { Avoidance of } \\
\text { Stimuli }\end{array}$} & Anxiety/Guilt & $\begin{array}{l}\text { "I feel a lot of guilt about } \\
\text { everything that happen to me, and } \\
\text { my cousin and relatives have to } \\
\text { die, but I escape." }\end{array}$ \\
\hline & $\begin{array}{l}\text { Emotional } \\
\text { Numbness }\end{array}$ & $\begin{array}{l}\text { "Many times, for no reason I will } \\
\text { cry and cry and cry, then I will } \\
\text { feel nothing." }\end{array}$ \\
\hline & $\begin{array}{l}\text { Physical } \\
\text { Symptoms }\end{array}$ & $\begin{array}{l}\text { "I am sick many times. I feel like I } \\
\text { cannot go on living like this." }\end{array}$ \\
\hline $\begin{array}{l}\text { Increased } \\
\text { Arousal }\end{array}$ & $\begin{array}{l}\text { Interpersonal } \\
\text { Relationship } \\
\text { Problems }\end{array}$ & $\begin{array}{l}\text { "I still fight with people at work, } \\
\text { because I don't have a family like } \\
\text { many people do. I never used to } \\
\text { fight, but now many times I feel a } \\
\text { big anger." }\end{array}$ \\
\hline
\end{tabular}


mental-health services, attitudes toward counseling, and resettlement issues. 


\section{CHAPTER FIVE}

\section{DISCUSSION AND CONCLUSIONS}

\section{Discussion of Results}

Because the Cambodians who survived the Khmer Rouge rule have been exposed to an existence of prolonged trauma, post-traumatic stress disorder is a serious mental-health concern among Cambodians today. The purpose of this study was to examine the existence and evidence of this disorder among refugee and resettled Cambodians, taking into account themes affecting the manifestation of post-traumatic stress. The diagnostic parameters from the DSM-III-R were used in assessing PTSD symptoms experienced. Interviews along the Thailand border refugee camps, phenomenological interviews conducted among resettled refugees, as well as follow-up interviews conducted 2 years following initial interviews were the way this study was conducted. Findings include an exploration of PTSD through derived themes relating to the Cambodians' trauma. These themes include adjustment and resettlement issues, symptoms of PTSD, spiritual issues, issues related to trust, the importance of the family, and looking to the future as a means of coping with PTSD symptoms. These established themes offer a wider view of the Cambodian post-trauma experience.

\section{Informal Thailand Survey}

As all subjects interviewed reported symptoms that fell within the 
diagnostic criteria of DSM-III-R categories constituting PTSD, the indications of these findings point toward the alarming rate that PTSD symptoms are experienced within the refugee camps of Thailand. Table 1 notes the number of symptoms and look at the manifested symptoms reported. Of utmost importance, however, is that those subjects interviewed did not perceive themselves as suffering from mental health concerns. This could be a result of concern over stigmatization, distress over a fear that their resettlement status could somehow be jeopardized, or is merely a result of the Cambodian attitude of accepting life as "a sea of sufferings"--the stress and strain of daily living considered a normal part of life and the lot of every human being (Ith, 1993, p. 18).

For many of those interviewed, the reported trauma had occurred years prior to the interview during the reign of the Khmer Rouge (19751979). However, during the time of the interviews, the traumatic events and experiences were of ten described as vividly as though they had just happened. Indeed, interviews included charged affect and emotion.

A persistent theme of the subjects interviewed relating to coping with PTSD symptoms was the hope of being resettled, thus a hope for the future. Often this hope was referred to in a discussion of how they dealt with their painful memories and other PTSD symptoms. It became apparent that while the refugees were in the camps of Thailand, they did not regard their symptoms as serious as long as there was hope for the future in being resettled in an accepting country. It seemed to be the sentiment that upon arrival in the accepting country of resettlement, these symptoms would disappear, and all would be well. Although the raw data obtained from the interviews alone could not attest to this assumption, through the course of 
the content of the interviews, this belief persisted as a dominant focus of the symptoms discussed with the subjects.

Most subjects interviewed openly expressed hope for the future through possible resettlement (theme 1 and theme 6 ) as well as an intense fear of repatriation back to Cambodia. Both of these served to "mask" worries or anxieties related to experienced trauma. Of those who had already been accepted for resettlement, there was a sense of breathless anticipation as well as a fear that something might sabotage the resettlement process and all hopes for a future life. Much emotional energy was wrapped up in these issues of repatriation or resettlement. Because of the importance of resettlement, eliciting help for mental difficulties was not done readily by the refugees, especially by those who were already accepted for future resettlement. These lucky refugees had a hope that others clung to, and expressed that they were preparing for resettlement by studying America, American culture and customs, and the English language.

It was felt that the amount of self-disclosure during these interviews was restrained and limited. Many subjects were initially hesitant to talk, but after a short time they appeared more at ease, as evidenced by their talking more freely of losses experienced during Pol Pot's reign, including the loss of family members during this time. The consulting psychiatrist in the camps also expressed surprise at the outcomes of the interviews and stated that the amount of information obtained was respectable, considering that Cambodians are usually hesitant to discuss mental problems.

One possible reason contributing to the effectiveness of the 
interviews is that in the Cambodian society, individuals are of ten seen in the context of their whole family. Thus, if the parents are well respected and thought of highly, the same will be true for their children. This proved to be the case at the time the interviews were conducted. My parents and I had an intimate, long-term connection with the camps through intensive relief work, and we were distantly known and trusted by many of the subjects.

One surprising fact about the interviews was that all subjects interviewed fit the diagnostic parameters of PTSD. In spite of the interview results, camp population, and mental health center reports, however, few Cambodian refugees sought help for mental problems. Keeping in mind cultural elements associated with privacy and verbal norms, this question was broached following the interviews to several randomly picked refugee camp inhabitants. I sensed fear and hesitation during the interviews by the subjects who explained that the refugees in the camps live in fear of being placed on the "mental health holding list." When put on this list the refugee must be symptom-free for 1 year to be considered for departure. This is a difficult burden for anyone living in a refugee camp, and explains the secrecy and few numbers of people willing to go to the mental health centers. Those refugees who are vocal about mental health complaints risk the chance of being rejected by a third country for resettlement. Excessive worry about the future (theme 6) characterized many of the refugee camp interviews because many of the subjects interviewed had not been accepted by an accepting country for resettlement.

In reference to symptoms experienced by the refugees (theme 2), 
those symptoms manifested were similar to those reported by subjects interviewed in the United States following resettlement. During the interviews it was important to note those symptoms directly related to PTSD. For example, many subjects reported excessive worry; however, this worry was primarily evidenced as a result of distress over future resettlement and repatriation concerns. Table 1 also indicates that a large number of individuals experience symptoms which fall under the diagnostic category "Avoidance of Stimuli." This is compatible with the Cambodian culture. For example, aggression, outbursts of anger, and negative acting-out behaviors, symptoms which would fall under the "Increased Arousal" category, are culturally inappropriate. The symptom mentioned most frequently was nightmares ("Avoidance of Stimuli" category).

Physical symptoms were the next most commonly mentioned symptom which fits the PTSD diagnostic criteria according to the DSM-IIIR. The majority of the refugees' physical complaints were actually psychosomatic or stress-related. As is consistent with Asian attitudes toward mental illness, physical symptoms are seen as being the "accepted" way of expressing psychological complaints (Sue \& Sue, 1990, p. 199). Ith (1993) states that

somatization is very prevalent among the Southeast Asian refugees. Patients under stress will seek help for headaches, insomnia, palpitation, dizziness, aches and pains, etc. They of ten make their own diagnosis to account for those bodily complaints: 'weak nervous system or neurasthenia' for chronic fatigability, head aches, poor memory, or inability to concentrate; 'weak heart' for palpitation, panicky feelings, dizziness, and fainting; 'weak kidney' for low back pain, sexual dysfunctions, impotence; 'weak stomach or weak liver' for indigestion and abdominal pains, etc. (p. 18)

For this reason, it was important to watch for such signs, and indeed, many such symptoms were described, which, after further probing, 
appeared to be psychosomatic in nature, "accessible" complaints for mental stresses and problems.

The psychiatrist supervising the refugee camp mental health clinic (personal communication, Svensberg, 1991) confirmed that the symptoms found in Table 1 were also those seen most often in the psychiatric ward in the camp.

Many of those refugees interviewed reported a reliance on a spiritual issues for peace and guidance in coping with many symptoms of PTSD. Interestingly, because Buddhism was banned and religion was discouraged during the Khmer Rouge rule, many Cambodians, while living in the refugee camps, sought alternative methods for obtaining peace in an effort to cope with reported PTSD symptoms. This search was partly a result of a crumbled faith and trust (theme 4) in Buddhism, as many subjects reported during the interviews that Buddhism "had failed when they most needed it." For this reason, churches of all faiths and denominations thrived in the refugee camps. Some subjects reported belonging to several churches in the camps, in the hope that this would be to their benefit.

At the onset of many of the interviews conducted in the camps, the subjects reportedly stated, "I will talk to you. I can trust you." Theme 4, trust, was often mentioned, and was a dominant issue in the interviews. This is not surprising, considering the fact that Pol Pot and the Khmer Rouge were themselves Cambodians, and were the ones responsible for the killings and traumas experienced. Cambodians were often responsible for killing members of their own family, the ultimate betrayal of trust in Cambodian society according to Cambodian cultural 
norms. Trust was severely shaken during this time, and it was only by not trusting that many were able to survive.

Stripped of all earthly belongings, many Cambodians escaped to the refugee camps with only a family member (theme 5). Those who did arrive with family were considered by others as among the fortunate few. Surviving family members lived together closely in the cramped quarters of the refugee camps, relying and trusting only each other. In response to interview questions, many subjects reported that they would only share such information as they were sharing then (PTSD symptoms)--within the privacy of their own family. When asked if they would ever talk to a counselor, the unanimous response was "no," that they would keep it within the family. The importance Cambodians place on the family cannot be emphasized enough. Ith (1993) maintains that "for emotional and instrumental support, the refugees relied primarily on their own circle of family, relatives and friends" (p. 20).

\section{Initial U.S. Surveys}

Theme 1

As emphasized in theme 1, the Cambodian's adjustment to resettlement continues to be an ongoing process filled with negatives and challenges, blessings and hopes. It also serves to compound PTSD symptoms. Upon arrival in a new country, the refugee is faced with a myriad of problems. In the interviews, some of these problems included intense homesickness, worries about the future, loneliness, language barriers, and missing various aspects of Cambodian life. Complications in adjustment and disillusionment, along with culture shock, were noted as a norm and proved prevalent among the three interviews conducted with the 
resettled Cambodian subjects.

After 2 years, the process of adjusting continued as a theme of the interviews, illustrating that it continues to be an ongoing process. Aspects of adjustment that continue to be challenging include such areas as language and various cultural issues and differences.

Other cultural and adjustment difficulties compounding PTSD included simple, daily aspects of life, such as differences in food, differences in greeting people, and other cultural variations. As an example, it was mentioned by Miss $C$ that Westerners are more forward in their introductions and greetings than she is used to. Even adjustment issues such as wearing a certain kind of clothing and not being able to buy certain things that they were used to in Cambodia were mentioned. Other more encompassing aspects of adjustment were also present; for example, Mr. B mentioned space. In America everything is very spread out, which Mr. B stated made him feel unsafe and insecure. He missed the close-knit villages and towns that characterize Cambodia. When he felt unsafe about the openness of America, he missed Cambodia. These feelings sometimes prompted nightmares, which resulted in Mr. B fearing sleep. Thus, all these factors combine to make adjustment to a new life challenging, thereby serving to compound PTSD symptoms.

There was an added emphasis on problems of adjustment in the initial interviews conducted when compared to the follow-up interviews. In the initial interviews, culture shock was seen as contributing to adjustment problems. In the follow-up interviews, a much more accepting attitude was evidenced by Miss $\mathrm{A}$ and Miss $\mathrm{C}$ towards adjustment and issues related with adjustment. It was felt that through this attitude of acceptance of 
adjustment issues, issues relating to PTSD and symptoms of PTSD could be acknowledged rather than masked by adjustment concerns. Although in the initial interviews, adjustment stresses were blurred with PTSD symptoms resulting from trauma, the follow-up interviews presented with more definition between adjustment concerns and stresses as separated from stress and symptoms relating to experienced trauma.

Mr. B, however, presented a more restless profile and the issues between the stress involved in resettlement and stress as a result of trauma proved more severely blurred. This could be a result of his recent visit to Cambodia. He stated that he did not want to return to Cambodia to live because of the instability of the country; however, he did miss it, and was having a very difficult time adjusting to American life, especially after returning home from his visit. The return visit to Cambodia triggered memories and thus symptoms of PTSD not previously experienced by Mr. B . Other differences between the initial interviews and the follow-up interviews include those aspects of adjustment which were emphasized. In the initial interviews, aspects such as language and getting familiar with services offered, including such simple functions as going to the store, were emphasized as causing much stress. However, in the follow-up interviews, more encompassing adjustment issues were mentioned, on one hand (such as space and distance), and more detailed differences such as the availability of missed Cambodian items were mentioned.

It is felt, however, that the period of time between the initial and follow-up interviews was sufficient in reducing the stress affecting PTSD symptoms. This was evidenced by the way PTSD symptoms were recognized more clearly by the subjects in the follow-up interviews as 
compared to the initial interviews. During the initial interviews, many of the symptoms seemed to have been "masked" by their recent arrival to the U.S. They were not as well defined by the subjects as in the follow-up interviews.

Theme 2

Symptoms (theme 2) experienced by the three subjects in the initial phenomenological interviews were extensive and wide-ranging. They proved to be similar in nature to those of other victims of PTSD in the refugee camp, as well as those experienced by the American Vietnam veterans. A symptom that was repeatedly mentioned was that of nightmares. The nature of these nightmares was usually in reference to witnessed killings, or to deceased family or friends. Physical symptoms were also prominently mentioned. A few other reported symptoms included the following: crying for no reason, feeling extremely sad, feeling physical pain for no medical reason, flashbacks, irritability, experiencing the trauma over again as a result of some external factor triggering the experience, a wandering mind, obsessing over details, feeling excessive guilt, interpersonal relationship problems, and emotional numbness.

Most of the subjects had experienced these symptoms since 1979, following the Khmer Rouge rule. Following adjustment issues, symptoms of PTSD proved to be one of the strongest themes among resettled

Cambodians. Symptoms pervaded most aspects of the subjects' lives, influencing them in multiple domains. Usually, the subjects interviewed were not directly aware that their symptoms were a result of trauma experienced. None of them, except Miss A, had a concept of trauma and its effects, and the relation of mental health to these symptoms. For example, 
it was not appropriate to ask if the subject felt depressed because most Cambodians do not know what is meant by depression. They could say that they were sad, or that their head hurt, but they could not answer if they were depressed. They would most likely respond that, of course they were sad, because of the physical symptom they were experiencing. Thus, symptoms were "dropped" unintentionally, unsolicited, from the subjects throughout the entire interview. For some, symptoms were more pronounced than for others.

Theme 3

A reliance on a spiritual issues (theme 3 ) as a means for coping with many of the reported PTSD symptoms was an unexpected theme among the initial phenomenological interviews. This concept, however, proved very dominant in the case of each subject. Included in the Eastern concept of spiritual issues is the concept of peace, harmony, symmetry, unity in one accord, and the concept of believing in fate and the natural order of things. Also, a deep respect for nature and the concept of religion and respect are embodied in this theme.

Studies on Eastern religions emphasize the theme that spiritual issues are utilized in dealing with suffering as well. It is obvious that spiritual beliefs play a part in coping with PTSD in the manner in which the subjects approach their symptoms. Mr. B mentioned going to the temple at least once a month in order to obtain peace. He also mentioned other activities he engaged in for the sake of maintaining harmony in his life on a spiritual sense and with people and with nature. Miss A mentioned her reliance on her religion as a means of coping with many symptoms and pain that she experienced. Peace was mentioned throughout Miss C's interview 
as a dominant standard she strives toward in order to cope with past trauma.

Harmony and peace also embody the culture of the Cambodian people. By nature, they are very peaceful, non-aggressive people, who tend to avoid direct confrontation.

The concept of peace is also influenced by Theravada Buddhism. The basic concepts are the unity of all life and the ultimate spiritual perfectibility and equality of all mankind. The concepts also stress the acceptance of the secular social order, religious detachment from worldly affairs, and the possibility of altering one's status through a combination of individual merit and reincarnation.

Theme 4

Trust (theme 4) was another theme that arose from the interviews, first evidenced among subjects interviewed in the refugee camps. Each subject interviewed in the U.S. mentioned it several times through the course of the interview as well. This is not surprising, however, considering the blatant betrayal by the Khmer Rouge. In order to survive the harsh environment of the refugee camps, it was often mentioned that no one could be trusted.

Miss $C$ stated that, to this day, she does not know where her father is. She often dreams of her grandmother, to whom she was very close. Family was repeatedly mentioned during each interview. It was obvious that it was an integral part of each subject's life. For Mr. B, his family was a major source of comfort and the reason for coping with PTSD symptoms. For Miss A, the loss of family members enveloped all PTSD symptoms. For each subject, dreams centered around lost family members. 
Theme 5

During the Khmer Rouge rule, most families (theme 5) lost at least one of their members. Many families were destroyed altogether, and others were split apart, never to be rejoined. Because families are an integral source of dealing with emotions and psychological pain, this loss is especially severe and serious as it relates to coping with symptoms and trauma resulting in PTSD. Many Cambodians report family members who are missing, and the uncertainty of whether or not they are dead or alive is a tremendous source of stress and anxiety.

Theme 6

The future (theme 6) was also frequently referred to by resettled Cambodians as a coping mechanism for dealing with PTSD symptoms. It was also referred to as a symptom. In the phenomenological interviews, the future was repeatedly brought up in these contexts as well. Miss C referred to the future with hope, as a source for helping her to "keep going on." Mr. B referred to the future also as a source of hope, and saw the future through the eyes of his children. Miss A stated, "I have a plan for the future. I have dreams now." It would appear that the future is clung to as a hope and as a source of dealing with the intense pain of certain PTSD symptoms. The future is wrapped up in family, as well, as the subjects mentioned the future of their children or young Cambodians as a great source of hope and comfort in coping with a traumatized past.

\section{Follow-up Phenomenological Interviews}

Adjustment problems (theme 1) continue to compound PTSD symptoms even after more than 4 years of resettlement within the United 
States. Many times these problems associated with adjustment were confused with PTSD symptoms, and indeed they are often a mirror of each other. Adjustment was focused on more heavily by Mr. B (Appendix C, Thick Description \#5) in the follow-up interview as compared to the initial U.S. interview. Reasons for this could include the fact that he is older than the other subjects, has more happy memories associated with his homeland, and has had a more difficult time cutting ties to his homeland. Also, Mr. B is married; he related that his wife was also having a very difficult time adjusting to life in America. Miss $\mathrm{A}$ and Miss $\mathrm{C}$ evidenced more of an attitude of continuing to anticipate better and easier adjustment which could be a result of their younger age, past experiences, and ease in accepting new ideas and thinking. Mr. B also directly mentioned his age and that he felt younger Cambodians did have an easier time of adjusting to cultural changes and a new way of life.

In the follow-up interviews, it was interesting that many of the symptoms (theme 2) were new--a result of recent events that triggered the memory of a forgotten trauma. In the case of $\mathrm{Mr} . \mathrm{B}$, his visit to Cambodia had triggered memories of many things that he had blocked out of consciousness. In the case of Miss $C$, forgotten memories of the traumatic death of her beloved sister were restored by a cousin who recently resettled in the United States. This memory had not been mentioned in the initial interview, and the symptoms mentioned at that time were quite possibly a result of the trauma that was blocked from consciousness. In regard to Miss $A$, therapy has unearthed memories, and their resulting pain, which have resulted in an escalation of nightmares. Other symptoms, however, such as her physical pain, have decreased since engaging in 
therapy. Each of the three subjects interviewed in the follow-up interviews continued to evidence symptoms congruent to a diagnosis of PTSD as illustrated by Tables $8-10$.

Miss $C$ stated that since the war, no one in Cambodia could be trusted (theme 4). She stated that this was her most feared aspect of postKhmer Rouge life. She could not trust anyone, not even her own family. Mr. B referred to trust five different times during his interview. One such comment (unrelated to the interview questions) was, "There are many dishonest people in the world." At the end of the interview with Miss A, she stated, "I can trust you, as I remember you as a child, playing with us in the refugee camps."

In the follow-up interviews, one of the key aspects of coping with PTSD symptoms included family (theme 5). Miss A related that since our last interview, she had devoted much time and affection to a new niece. She stated "I feel my niece being born helped me more than the psychologist." With the emphasis placed on family, Miss A's reasoning can be seen. Mr. B stated that it is his children who give him hope and keep him going when he gets "down." His wife is the one he turns to with his problems and when certain PTSD symptoms become severe. Miss C revealed that her lack of family and her nightmares relating to family are the most troubling of all her symptoms. Sue and Sue state that "mental illness represented a failure of the family" (p. 198) in regard to Indochinese patient values. Thus, family is even a present theme in help-seeking behavior for mental illness.

The future (theme 6), even after 4 years of resettlement, continues to be anticipated. During the refugee camp interviews, the 
future as it pertains to resettlement or repatriation was emphasized, and the future of resettlement and immediate concerns with adjustment and "getting on with one's life" were emphasized during initial U.S. interviews. In the follow-up interviews, the future of the country of Cambodia was focused on. There was a quality of missing the "old" country, and a reminiscent factor of waiting, longing, and anticipating the future as it relates to returning to Cambodia someday. Miss A stated that, "When I think of Cambodia I have a big sadness. I want my future to include my homeland of Cambodia." Regarding a future through his children, Mr. B stated: "I want for my children to have a good future." Miss C relayed, "Maybe in the future I will forget," and, "I never gave up because I think maybe I will find happiness someday."

\section{Cambodian Trauma Related to the Veteran's Trauma}

Sandrick (1990) states that a common manifestation of post-trauma symptoms among veterans includes alcohol abuse. This is especially the case for depression. According to the three interviews conducted for this study, symptoms tended to be manifested through psychosomatic means, especially depression.

Other differences between the way symptoms are emphasized according to Cambodians versus American veterans can be seen through illustration of the established themes in this study. Although it is beyond the scope of this study to investigate themes among veterans, this study points toward the importance of an increased understanding and awareness of Cambodian issues related to past trauma as they can/do differ from Veterans' issues. It is felt that an awareness of this fact is necessary in the treatment of Cambodian trauma victims. 


\section{Limitations of the Study}

Limitations of the study are evidenced through a lack of concrete data from studies done determining the exact prevalence rate of PTSD among post-1975 Cambodian survivors. While this study offered an understanding of the depth of the trauma experienced, and symptoms manifested, a more comprehensive view of losses experienced, and families intact vs. broken apart would aid in an understanding of the present study.

There are natural concerns of the limitation of the research undertaken in the present study as well. It is regretted that more time could not have been spent with each subject, as it is felt that further information could have been obtained, furthering an expanded understanding and providing a broader knowledge-base for the present study.

Furthered exploration of the manifestation of PTSD as experienced among Vietnam veterans as compared to the manifestation of PTSD among Cambodians would have been beneficial to the present study. This would have allowed a more comprehensive look at the differences needed to be employed in developing a counseling modality of treatment for Cambodians that differs from those treatment programs already offered to Vietnam veterans diagnosed with PTSD.

This study is also not exhaustive of the themes and issues related to PTSD. While themes were gathered from the interviews conducted, it is felt that following more extensive interviewing and data collecting, more themes and the dominance of themes in relation to each other could be examined. This would benefit the present study in an understanding of 
the phenomena of PTSD as a whole.

The study is also extremely narrow and limited in the pool of subjects interviewed. More decisive findings could result from a larger number of subjects being interviewed.

This study is also limited in its application to Cambodians only. There is no reference to other refugee or resettled populations and the affects this study could have in relation to these other populations.

Finally, it is inevitable that the interviewer employing a phenomenological method will have values, unavoidable biases, preconceptions, and assumptions which influence the research. Instead of minimizing biases, the phenomenologist has attempted to recognize them.

\section{$\underline{\text { Recommendations and Conclusions }}$}

Several recommendations need to be made as a result of this research. It is believed that, from the interviews that have been done, there needs to be an added consciousness of culture, customs, and background experiences of the Cambodian people among the counseling community.

It is also felt that counselors need to be aware of the strong possibilities of PTSD symptoms in an effort to recognize them in Cambodian clients. While keeping in mind the Buddhist norms as well as social and cultural norms of behavior, one needs to be aware that when an Indochinese does seek treatment, it most likely is of a serious nature. This study also needs to be done on a larger scale in an attempt to determine the exact prevalence of PTSD among the resettled and repatriated Indochinese.

To a people abducted by tragic experiences, PTSD among the Indochinese continues to be a serious mental-health problem. Drawing upon 
the phenomenological interviews as well as the evidence of high levels of PTSD in Thailand refugee camps, not only is PTSD prevalent among the Indochinese, it is also experienced in a different way from that of the Vietnam veterans. This was illustrated through the cultural manifestations.

The degree to which PTSD symptoms were manifested among the interviewees is overwhelming. Not only are the results startling, they point dramatically toward the increasing problem of PTSD among resettled Cambodians and reveal that PTSD is indeed a growing mental health concern in today's society which deserves immediate attention.

It can be said that almost all Cambodians, with the exception of perhaps the very young children, will continue to suffer for many years to come as a consequence of experienced trauma, uprooting, the removal from customary social support network systems, and the compounding of PTSD symptoms by adjustment and resettlement factors.

For future research, counseling modalities related to the effective healing of PTSD among Cambodian victims of trauma need to be established based on an understanding of the whole phenomena of themes relating to PTSD. Comprehensive treatment approaches focusing on Cambodian symptomology and the coping mechanisms of these symptoms need to be established to properly treat those victims still suffering from experienced trauma. Further research should focus on areas of the assessment PTSD and the degree to which symptoms experienced are affecting the victim's life in a negative fashion. It is only then that mental-health professionals can make a difference in the treatment of post-traumatic stress disorder among resettled and repatriated Cambodians. 
APPENDIX A

REFUGEE CAMP PASS 
APPENDIX B

INITIAL INTERVIEW AND

FOLLOW-UP QUESTIONS 
Appendix B

PTSD Interview Focus Questions

Interviewer: Jolene Aitken

Interview \#

Date

Name/code of client

Place of interview

1. Introduction: My name, my research, and the nature of the interview. Ask for, and receive their signed consent to being interviewed.

2. Explain fully, the nature of the research, and the full extent of and limitations to confidentiality as well as tape-recording of interview.

3. Establish rapport by asking vague, polite questions .

Show a genuine interest in the subject

Get data on subject such as age, sex, family size, occupation, etc.

4. Ask the following questions. Questions need not be followed in any particular order, however all categories should be covered at some point in the interview.

5. QUESTIONS:

How are you doing?

How is the health of your family?

How is your health?

Are you on any medications? If so, for what?

What is your medical history?

Family history.

Number of children?

Adjustment of children?

Number of family resettled in the U.S.?

What is your birth-order within your immediate family?

How do you find your new life in the United States?

What have you done to adjust better?

What services have you made use of/taken advantage of? (churches, community agencies and services, etc.)

Do you miss Cambodia?

What do you miss the most?

What was it like, growing up?

What kind of family did you come from?

What did your father do? mother? What did they hope you would do?

What was life like in Cambodia before you fled the country?

Why did you decide to leave Cambodia?

Under what conditions did you leave? 
What were your experiences during the Pol Pot regime?

How many of your family survived?

How has your family coped with the death of other members?

Do you talk about the trauma?

What was the effects of this experience on your life?

How have you changed?

How has your family changed?

How long was your stay it the refugee camps?

What was this experience like?

family?

What was the affect of the refugee camps on your life? The life of

What do you miss about the refugee camps?

Compare and Contrast life in Cambodia with life in the U.S.

(Issues dealing with PTSD)

How often do you remember happy times in Cambodia?

How often do you remember life in Cambodia?

How often do you remember the Pol Pot years in Cambodia?

how of ten do you think of deceased relatives?

When (at what time of the day, month, year, ) do you find your thoughts drifting back to memories the most?

What is your reaction to these thoughts?

How do you feel when you remember Cambodia?

do you ever plan to return to Cambodia?

Do you have some memories that are very painful to remember?

Can you share these painful memories with me?

What do you feel when you remember these painful memories?

how have you been able to deal with the sad, painful memories?

When do you think about these memories the least?

Has it gotten better or worse over time? As time has passed?

Do you feel your family and friends also have some painful, sad memories of Cambodia? Do they talk about it?

Do you ever have trouble sleeping? Eating? Laughing?

Do you ever get flash-backs? 
Appendix B Continued

FOLLOW-UP PTSD INTERVIEW QUESTIONS

Interviewer: Jolene Aitken

Interview \#

Date

Name/code of subject

Setting of interview

1. Introduce myself. Remind subject of previous interview.

2. Inform subject of research and paper completed on research. Thank subject.

3. Inform subject of continuation of research and ask questions pertaining to their willingness to be involved again. Receive signed consent.

4. Establish rapport by asking questions pertaining to work, weather, etc.

5. Ask the following questions. Questions need not be followed in any particular order, however all categories should be covered at some point int he interview.

\section{QUESTIONS:}

General.

How are you doing?

How is your work? (follow through with this question).

How is the health of your family?

How is your health?

How are you children doing?

Any major illnesses, surgeries, etc? On any medications?

Family status.

Ask about certain members of family - (example = elderly grandparents).

How are you adjusting to life in the U.S.?

Do you feel American?

Do you feel you have adjusted better since I have talked to you last?

What changes have you made it the last two years?

Do you still miss Cambodia?

What do you miss the most?

What do you find yourself remembering the most?

What about family? Family left in Cambodia?

Recap for subject experience in Cambodia, escape, and life during Pol 
Pot regime. Record what subject expounds on.

Memories:

Do you still remember these experiences?

How is your family coping? Has two years made a difference?

Has the difference been greater for some members than for others?

Do you notice a difference in coping with/for yourself?

Do you still miss Cambodia?

What memory do you recall the most of ten?

Does your family talk about these experiences and memories?

Who do you talk to?

Compare and Contrast life in Cambodia with life in the U.S.

(Issues dealing with PTSD)

How of ten do you remember life in Cambodia?

How of ten do you remember life in the refugee camp?

How of ten do you remember life during the Pol Pot rule?

Do you/have you kept in contact with friends and/or family in Cambodia?

Have you kept in contact with friends/family in the refugee camps?

How of ten do you think of deceased relatives?

When (at what time of the day, month, year,) do you find your thoughts drifting back to memories the most?

What is your reaction to these thoughts?

How do you feel when you remember CambodIa?

Do you ever plan to return to Cambodia?

What do you feel when you remember these painful memories?

When do you think about these memories the least?

has it gotten better or worse over time?

Do you feel your family and friends also have some painful, sad memories of Cambodia? Do they talk about it?

Do you ever have trouble sleeping? Eating?

(Watch for, or if appropriate, ask directly about symptoms related to PTSD such as anxiety, depression, flashbacks, nightmares, relationship problems, hyper-alertness, emotional numbness, insomnia, withdrawal, excessive worrying, irritability, over-aggressiveness, panics, feelings that you were back at the trauma, etc.)

Have your painful memories ever kept you at home, made you unable to do something, go somewhere, etc?

Would you rather talk about these memories, or keep them inside?

Have you received counseling?

If YES = Has it helped? What was the race of your counselor? What did you work on in counseling? How long have you gone to counseling? Was your whole family involved? Did you also use traditional medicine?

If NO = Who do you turn to for help with mental problem? Why would you/wouldn't you go to counseling? Would you consider it in the future?

Do you know anyone who has gone to counseling? what did you think of them? 
Have you gone to counseling, or do you know anyone who has? Do you use some traditional medicines? Such as those used for headaches?

How often do you have head-aches?

If you have so many painful memories, who will you go for help from?

Do you find you have stress since arriving in America?

What is the greatest cultural adjustment you have had since arriving in the United States?

What are your hopes and dreams for the future?

Where would you like to see yourself in 10, 20, 30 years?

6. Thank them for their participation, and for being so honest and open. Recognize the difficulty in talking about this.

7. If the need is indicated, recommend counseling only after fully explaining what it is.

8. Set up appointment for feed-back. 
APPENDIX C

THICK DESCRIPTIONS \#1-6 


\section{CASE ONE, SUBJECT A}

Miss A, 33 years old, has lived in the United States for over two years. I agreed to meet with her in her apartment in Loma Linda, California, where she lives with her sister who works at the hospital, there. I had been referred to Miss A by a refugee specialist, after being advised that Miss A experienced PTSD symptoms. Miss A was sitting on the couch when I arrived. She seemed agreeable to and open to the interviewing process, and eager to talk. As we began the interview, I opened with a general question about her health. As expected, she assured me that she was okay, and feeling fine. I was to find later in the interview, that this was not so, though, and that she was very very ill. After explaining the nature of my research, I asked for her consent, telling her again, (I had talked to her on the phone to get her consent), that this was voluntary and that she was not obligated to say anything or to even do this. She assured me that the interview was something that she wanted to do. She asked me where to begin, and I told her to begin at the beginning. She seemed somewhat hesitant to begin, and asked if she had to begin where the sadness started, and I told her to begin as far back as she can remember, if she wants. So Miss A preceded to tell me about herself and her life. She told me the basics. Miss $\mathrm{A}$ is from Kompongchan city inside Cambodia. She has four sisters and one brother. Her family lived in this little city where her father owned and ran a store. As is typical in Asia, the job was a joint family effort, and everyone in the family was involved. From a young age Miss $A$ worked in the store, keeping track of the accounts and merchandise orders. The store was a variety store, and they sold everything from pots and pans to imported apples from third-world countries. Miss A did go to school, working in the 
mornings and attending school in the after-noon. She was very happy with her life, and did not consider the work she did in the store, to be work, because she enjoyed it so much. She was very close to her parents, especially her mother. Her other three sisters and brother opted to go on through school, and did not want to work in the store for the rest of their lives, but Miss A was devoted to her parents and to the store.

She was quite relaxed, yet seemed somewhat sad as she talked about these memories. She smiled when she remembered the store, and went into great detail describing what the store sold, and her duties. She also kept referring to her parents, especially her mother, whom she spent much of her time with. She said she was closer to her mother than any of the other children in the family were.

When Miss A turned 23 in 1973, she quit school because she did not want to go to college, but chose instead to help her parents full-time in the store with the accounting duties. She loved the work and loved her community. She remembered a lot of unrest in the country at this time, and her parents were upset over all the bombing and commotion. They were confused as to what was going on, and continually tried to get a radio to hear what the news was. While her family was not overly wealthy, they did have funds to send Miss A's brother and three younger sisters to college, leaving the youngest at home with the parents and Miss $A$. The youngest and Miss A became very close as well. The family was well-liked in the community, and her father had been educated at a university in Phom Phen.

In 1974 the trouble began. Early one morning there was banging at the door. When they answered it, they were met by Pol Pot soldiers. They forced themselves into the house, and took her father by the arms, saying that they 
wanted to take him to a meeting. Confused and frantic, Miss A, along with her mother and sister asked and questioned the soldiers the next few days as to the where-a-bouts of her father. The Pol Pot soldiers kept repeating the same thing, "we took him away to reeducate him". When she asked if he was in prison, they promised that "no, he is not in prison". Despite what the soldiers said, though, they felt that he was in Prison, and would someday be released to them.

Meanwhile, the store had to be closed because the business was bad as a result of the turmoil caused by the disappearance of so many men from the city. Money was worth nothing any more. Bills equivalent to U.S. $\$ 500.00$ were floating around in the streets, but nobody wanted them. Everything was traded. Many people traded with the store. Many people were also worried because there were things and rumors said about bodies being dumped in rice fields some distance away from the city. No-one knew if this was true, because the Pol Pot soldiers controlled all the roads and everyone was told to remain in their homes. It wasn't long before the Pol Pot soldiers again knocked on the door demanding that Miss A and her younger sister, (age 17) go to the jungle to work in a special camp, which turned out to be a concentration camp. Miss A says,

"We work many hours from the morning at 5:00 until the night at 10:00. We have lights and must work even when it is dark and cold. We were very hungry and eat only a little bit of food. The soldier were very cruel to us and will kill someone who talks, so I must look down and be very quiet. I miss my father and mother and see my sister become thin. I think that she will die because she has no food, but I cannot talk to her or I will be kill". 
This all happened before the Pol Pot, Khmer Rouge take-over of the capital of Cambodia, Phom Phen. The Khmer Rouge took over Phom Phen a year after Miss A was sent to work in the forest with her sister. She saw hundreds and thousands of people from the city come to the country-side and be admitted to the work camp where she was. Miss A says, "Everyone who came thought that the United States will bomb the city of Phom Phen, so many people did not leave with clothes or with enough food. When I am working I see many people who are taken to the forest to be killed. I know that they are killed because I see the bodies".

At this point in the interview, Miss A broke down sobbing. I could tell that she was visibly upset. I let her cry, offered her tissue, and informed her that we were not in a hurry, and that she could take her time. She apologized for crying, but I reassured her that it was okay. Through her sobs, very slowly and deliberately she told me the following:

"I see many of my people die. I see the head of some men separated from the body in the forest when I went to the bathroom. I always worried about my father and mother. I did not see my mother for two years already and I cannot ask anyone who is new in the camp if they know about her. In 1978 I escape from the camp because I have to see my mother. When I go to her, she is very sick."

At this point in the interview, Miss A was visibly upset, again. She was shaken about talking about it, but also seemed upset about the fact that she was upset. She preceded to tell me about how she had taken care of her mother in a cold, drafty, wet, room with no food and no medicine. Her mother had what seemed to be a severe intestinal tract infection, and was in constant pain with constant diarrhea. She also had a very high fever. Miss A's younger 
sister had also escaped from the work camp, though not with Miss A.

Part of the Pol Pot regime was to be rid of all doctors and nurses and to return to the old way of healing and doing things. Miss A went daily to hunt for herbs and food to make her mother feel better, while her sister stayed at her mother's side. Miss A knew that her mother was about to die, so in one last effort, put her mother in a borrowed ox cart and pushed her nine miles to the Pol Pot "hospital", where there were many sick people. Afraid of being recognized as having escaped from the work camp, Miss A covered her head up and tried to keep out of main traffic of people. She was very frightened. Along the road there were many dead people. She always tried not to cry, but she could see that her mother was dying. She asked the Pol Pot lady in the "hospital" to help her mother, but the lady said, "let her die. She will die anyway. Your parents mean nothing. Anka is your parents. You live for the new order, Anka."

Miss $\mathrm{A}$, at this point in the interview, was crying again at the remembrance. She seemed upset, and I told her that she would not have to go on if it was too painful. She wanted to, however, and told of how the communist Pol Pot "nurse" told the girls (Miss A and her sister) that they should dump their mother's body in a pile with the others. The girls were horrified and shocked and refused to do that as their mother was still alive, and conscious. They begged to be able to take the body home in the cart. The nurse said okay, since it was 1:00 a.m., and no-one was around. At this point, Miss A said, she did not know what had happened to her other three sisters, her brother or her father. She only knew that she lived, and her youngest sister was starving. A little ways down the road, Miss A's mother died. They buried their mother behind their house, but had no casket. Miss 
A repeated this several times in the interview, and it was obvious that this fact upset her considerably.

Miss A began crying again. She said that she was frightened because she does not know now if her mother was really dead. She thinks that maybe her mother could have been alive, but unconscious, and the communist nurse lied about their mother dying soon, to make them get away from her. Miss A worries that her mother could have regained consciousness. She says that she was very weak and cannot remember all the detail of what happened but she dreams at the night all the time that something did happen to her mother because of her fault. Miss A told me that she cries every night. For the past six years she cannot remember when there was a night when she didn't cry and when she did not have a bad dream.

After her mother died, Miss A does not remember what happened, except that she fell in a heap on the ground and blacked-out. She was then taken by the Pol Pot soldiers to work in a camp again. She worked, as before, long hours with her sister. Her sister had been taken with her. Her sister got steadily weaker. One of the older sisters who had been studying in Phom Phen was brought to the same work camp as Miss A, but they could not acknowledge each other, and only gave a quick look. This sister was very weak also, and could not work so hard. She became thin. Miss A tried to give her some food but the soldiers caught her and force her to beat her sister. Then Miss A had to dig the hole where the soldier told her that her sister would be buried. Miss A cried and wanted to die. Many times she wanted to die. She was forced to watch the soldiers kill her sister and put her into the hole Miss A had dug. As Miss A talked of this, she was very nervous and very upset. The way she talked seemed to me that the experience was very close 
and very real to her. She sat on the couch the whole time with a box of tissue.

Miss A lived through the work camp experience with her younger sister, who, in spite of the long hard work and little food, did not die. Miss A remembers, "many people die around us because they are hungry and cannot have enough food to eat. The Pol Pot soldier give us much water in a bowl with only a little bit of rice. While we are working sometimes we find the beetle or herb to eat.

On December 12, 1979, the Vietnamese attacked, so all the Pol Pot communist forces went to fight in defence. This left the work camps empty for a few days, at which time many either returned to their villages or fled to the border of Thailand seeking safety in the refugee camps. Miss A returned briefly to her home, where she learned that one of her sisters had managed to get out of the country before it fell, and was living in Thailand. This news made Miss A very happy, so she and her sister prepared to make the escape to Thailand. She also learned that her father had been killed, as a neighbor had seen the body. Her brother and other sister were missing, and she still does not know if they managed to escape and are living in a third world country or if they were also killed.

Encouraged by the news that one of her sisters was alive and waiting in Thailand, Miss A arranged to escape to the border of Thailand with her sister, with the help of two guides who would direct them to their destination. The price was very expensive because guides were very much in demand, and if anyone was caught, it meant instant death. Miss A arranged with some guides who had been friends of the family. The journey took 17 days by foot and bicycle through the jungle. Miss A started to perspire and seemed visibly shaken. I too was Uncomfortable with all the pain being expressed, but tried 
to concentrate on what was being said.

Miss A told of how difficult the journey was. At several points both she and her sister became so weak the guides carried them in a hammock for several miles. She recalls seeing rice paddies filled with corpses. There were mines everywhere. If the party was seen, there was an understanding that the guard could abandon the girls, and the girls knew they would be raped. Miss A did not want to talk about some things that happened on this trip. She did say that they were seen several times along the trip, and eventually made it to the border without the guides. She didn't continue, as she said that it is a pain in her heart and she cannot talk about it. I did not push her. I asked her to jump ahead to what she would like to talk about. She wanted to skip the trip, but just told me that it was very difficult and sad. She was glad she and her sister did make it to the border camps, though, alive.

When in the refugee camps, she met her sister who had escaped all the pain. But she did not know how to relate to her. The girls arrived at the border camps in 1983. From here they were placed in refugee camps until 1985 when they were accepted to go to France. Miss A has spent the past five years in the United States, having lived two years in France.

Miss A says that it is upon arriving in Thailand that her pain began. She has excruciating pain all over her body. She cannot move, of ten, as the pain is so debilitating. She cannot go to sleep at night, and only sleeps for about one hour at a time before night mares wake her up. She gets angry at her sister often because she feels her sister does not understand her pain. She has night-mares at least three times a week, often every night for weeks, then a day will go by when she is okay, but the night-mares always return. Miss $\mathrm{A}$ is an Adventist, and she feels very guilty for the feelings that she has 
because she can't understand why God does not take away the pain when he knows how much she suffers. She prays very hard, but her pain remains. The pain was a central element to our interview. She feels pain all over her body. Her hair hurts, her finger-nails are in pain. The muscles all over her body are in continual pain. Many times she has been sure that she will die. She vomits all the time and finds it very difficult to eat. She went to the doctor while in the camps, but was scared to mention any mental problems for fear of not being able to resettled. So far, upon arriving in France and the United States, Miss A has gone to seven doctors, non of whom have asked her anything about her past, but rather have quickly given a diagnosis and some medicine for sleeping. While the sleeping pills help, it doesn't get rid of the pain. When I asked her what it is that she dreams about, she told me that she sees the killing and she is running and she cannot stop and she cannot stop the killing. She also sees her sister's and her mother's death. She always wishes that she can go and look for her father. She wonders if they are in a heap and that is how they are buried. She blames herself for their death and thinks all the time about how she could have prevented it. She feels that she does not deserve to be living.

She also began crying and said that she feels hate for the soldiers that killed her people, but she must not hate because she is a Christian. She prays and prays, but the pain will not go away. She tried not to think about it, but the pain is still there. Miss $A$ also talked about flashbacks. She suffers from these continually. Whenever a door slams she says that she jumps and sometimes lies on the floor, trembling. She is afraid to go out to the public because of this and doesn't want to be embarrassed. She also gets flashbacks when she hears her sister's voice sometimes, because she says that it sounds 
like her mother. Miss $\mathrm{A}$ is not sure if this is the reason she can not stand to be around her sister long, or not, but she feels that her sister does not understand her pain, and many times cannot even be in the same room with her. Sometimes her pain is so bad, she feels nothing. She can only lie in bed and it is so painful to do even the smallest things like going to the bathroom. She constantly has to fight to keep control of her mind and not to let it wander.

The physical symptoms of PTSD Miss A experiences, are numerous. As was mentioned, her hair hurts, her fingernails hurt, her back hurts, She is continually in pain and of ten cannot move because of it. She has had pain for the past seven years, and all eleven doctors she has gone to have not helped. Miss A did go to three psychologists, but not one of them asked her even one question about her past. Two of the three diagnosed her as having bipolar depression, and gave her anti-depressive drugs as well as sleeping pills.

While the interview lasted a very long time, I tried not to interject my biased opinions or feeling into what was being said. I tried to comment as little as possible so as not to influence her reactions. The interview was lengthy, but a good one, and she was very happy to talk to me, she said. She also told me that she had not talked to someone about this for over five years.

After listening and discussing the interview with Dr. Timothy Berry, Ph.D, I decided that the best thing I could do for Miss A, since she did ask for my help and advice, was to refer her to a Christian psychologist. I did do this, following the interview, in a follow-up telephone contact. 


\section{THICK DESCRIPTION \#2}

\section{CASE TWO, SUBJECT B}

The second subject interviewed, Mr. B, 43 years old, was selected randomly from a pool of names provided by a refugee specialist. Mr. B initially reported that he did not have any PTSD symptoms, but through the course of the interview, it was proved otherwise. The interview was very surprising, and showed me a great deal about the way PTSD can be manifested.

Mr. B currently lives in the ghettos of Chicago, his six year old little girl, three year old boy, 10 month old baby and wife and he all sharing a small, two bedroom apartment. Mr. B has lived in the United States for over three years. Our interview lasted several hours, and he told me his story of how he ended up in the United States.

Mr B came from a wealthy home in the capital of Cambodia, Phom Phen. He lived with his two sisters, a younger brother, and his parents in a beautiful home where they were fortunate to have maids, drivers and many of the luxuries of life. Mr. B spent his days is study to become a professor of history. His family valued education and it was $\mathrm{Mr}$. B's dream to continue his education to the highest degree possible. Disaster struck, however, when Pol Pot's soldiers invaded Phom Phen. Mr. B's family was with the masses as they made the exodus out of the city into the countryside. He recalls, "I was worried because something looked like it was wrong. No person knew what was happening. There were many rumor from the countryside. The rumor from the countryside was not good and I was frightened about this." At a check point on their way out of the city, the Khmer Rouge ordered the family to go to a certain village where they would be put to work in a labor camp "for the good 
of the 'Angka'" they were told. Not knowing what else to do, the family obeyed, but not before their T.V., their vehicle, and any other large valuables were taken away with the explanation of, "this all belongs to the new regime". While working in the labor camp, the family was fortunate enough not to be separated as most were.

Mr. B related these facts to me with much feeling. It was obvious he felt strongly about what he was saying, and seemed earnest and somewhat desperate to imprint on my mind the severity of the situation. While he is a quiet man by nature, he was very intense when relaying these experiences. Though the interview took place in February, he was sweating and continually dabbing at his forehead. Through-out the entire interview, however, he never broke down crying as subject Miss A did, though he did seem very upset, especially as the interview progressed. As with the other subjects, I attempted to merely help facilitate the process of remembering the experiences that would lend to revelation of the symptoms he currently suffered from.

While Mr. B was working in the work camp, there were loud speakers continually playing music and chants in dedication to the new Khmer Rouge regime. Weak and suffering from frequent dizzy spells, Mr. B accidentally addressed one of the Khmer Rouge soldiers as "teacher". Angry, and not wanting anything or any words uttered that referred to the old regime, $\mathrm{Mr}$. $\mathrm{B}$ was beaten, taken to another province, and put in jail. The jails at this time were over-crowded, and he received only a little food each day. He stayed there for over six months and watched many other cell mates die of malnutrition. Desperately he prayed to Buddha to bless him, but, as he said, "Buddha had left Cambodia. There was dying everywhere." Mr. B was eventually released to make room for more serious offenders. He told me of his 
night-marish experience of returning to his family and the work-camp since he was starving and weak, and did not know where else to go.

Upon arriving "home", he was glad that all his family members were alive, but horrified at the signs of starvation. He stayed hidden in the forest and sought out animals and roots for his family to eat and snuck them food during the night. One of his sisters already had advanced signs of malnutrition. He attempted to feed her, but he was caught and beaten and forced to kill his own sister. After this, Mr. B says,

"At that time I want to die many times. I don't want to live and see my family die or remember the killing. The Khmer Rouge also kill many of my fiend for no reason, just a small thing. One day when I am walking back from the work site, I see the killing, many killing of the people who did no mistake. Every day I think that I will be the next person to die. The Khmer Rouge try to kill us step by step. They want us to die by starvation. I work with 29 men, and all die except for me and another man. Before they are kill, 1 think that there is danger, so I escape in the night and look for food. Then I go to Thailand where I can find safety."

Mr. B also told of the inhumane experience of seeing his father die a brutal death. He later told me the details which are very traumatic and gross, but asked that I not mention them out of respect for his father. He did not want to talk of his father because he said the pain was very heavy on his heart. Mr. B's sister and mother also died of starvation. Mr. B remembers that his sister's husband was killed, and his sister had a new baby, but she did not have milk or food for it, so it died. His sister did not want to give the baby to the Khmer Rouge to be buried because she knew that they were cruel, so 
she buried it under the hut. His brother was able to escape with him, but stepped on a land mine a day from the border. Mr. B made it to safety all alone. He got married to a woman he had known in Phom Phen who had also been able to escape. They were married in the refugee camp. Mr. B says that he really wanted to have some family, and that is why he got married. He also said that his wife suffered, too. Repeatedly through-out the interview, Mr.B recalled his sister whom he felt he had murdered. He stated he still dreams of her, constantly, and can't get rid of her face.

The symptoms mentioned by Mr. B are many and varied. The biggest problem, he felt, was the anger. He said, "All the time I try not to have the memory because I have such a big anger. Sometimes I feel so big of anger that I cannot move. I feel I am frozen in one place. I feel this every time I have the memory." The memories, he told me, happen of ten and are often triggered by small external happenings such as faces and voices and certain noises. He is very happy when he doesn't have a bad dream, but that is not often. He and his wife both wake up often during the night from nightmares and restless sleeping. When asked what it is that his dreams are about, he said that they are always of the same thing; his family being killed, his mother starving, his sisters starving, his sister's death, and his father's death. Sometimes he has the chance to kill the men who did so much killing, but he doesn't do it.

During the day Mr. B continually remembers and relives the scenes in his mind, though he tries to block them out. Another thing that disturbed Mr. B considerably, are the lapses of time that go by and he doesn't realize it. He says that this doesn't happen often, but sometimes a large amount of time can go by without him realizing it.

Mr. B's physical symptom is a persistent sniffle that he has had ever 
since arriving in Thailand. He has been to three medical doctors about this, but they can find no physiological reason for his sniffle. He also does not know why he does this, but admits that it gets worse when he has memories of his past. When asked if he feels that the persistent sniffles are the result of his trauma, he did not know, but did know that they began after arriving in Thailand. He had thought, while in the refugee camps in Thailand, that they would leave upon resettlement in the United States, but this has not been the case. While it hasn't gotten worse, it also has not gotten better.

Finally, Mr. B has had difficulty getting along with his wife and kids. While he has a good job and is working hard, he wishes that he could be rid of the mental pain he has from the past. How does he cope with the memories? He usually tries to block them out of his head, and this works the best for him, he says. The nights are when he has the most difficult time because that's when his mind wanders, but he tries to stay busy with work so he will be very tired at night.

After discussing the interview with Dr. Berry, I suggested to Mr. B that he see a psychologist. He was very opposed to the idea, the cost being the major reason, although he also said that this was a personal matter of the heart, and other people could not understand. After having gone through so much pain, 1 was surprised at Mr. B courage. He was optimistic, and determined. He enjoyed talking with me and thanked me over and over again for letting him talk to me. I feel that the mere fact of talking about many of these suppressed memories was a comfort in itself. I thought it was interesting that he felt like I was doing him the favor, when he was really the one helping me out. I did notice that he put up a reserve in regards to certain issues like the death of his father, and the details involved with the death of some of his 
family. I can understand that this could be, perhaps, because of the Buddhist background $\mathrm{Mr}$. B is coming from. In closing, I'd also like to mention that Mr. B voiced many concerns about resettlement. The process of moving to another country had many worries associated with it. He voiced several concerns and adjustment issues he had not been aware of, or prepared for. 


\section{THICK DESCRIPTION \#3}

\section{CASE THREE, SUBJECT C}

Case three, Ms. C, 30 years old lives in Phoenix, AZ. She lives there with some friends who were also able to escape. Ms. C's story resembles those already given. She was randomly selected on from a pool of names. The only criterion being that she was female. While she is adjusting fine to life in the United States after resettlement, she does have some very sad and difficult times to deal with.

When the Khmer Rouge invaded Ms. C's village, her husband was among the first to go. A quite, gentle woman by nature, this upset Ms. C, and she says, "I had one little baby. I had only been married for one year. They take my husband and I never see him again. They also kill my baby and my baby died the most bad death that your mind can think." Ms. C, having gone to school up to the college level, prepared immediately to escape with her brother and mother. Somehow her planned escape leaked out, and before she got away, her home was set on fire. To this day she says she has a hard time when she smells smoke. Many times she dreams of smoke and her house burning. When she escaped, the next morning, her mother, brother and she ran by night and hid in the jungle during the day. She saw many bodies along the way and she saw how some of these people were killed. She recognized some people as friends and was very sick. She was frightened, and only wanted to reach safety of Thailand. There was very little food to eat. Her father had disappeared with the Khmer Rouge. He had told Ms. C that he had been selected because of his education to help the Khmer Rouge govern the country. They also told him that he would write about his new position. Ms. C, her brother, and mom feared because they had not heard from him. Ms. 
C said, "When I escape and see the many dead people along the road, I know that the reason is because of the starvation, but $\mathrm{I}$ know that the reason is also because of the Pol Pot people who kill their own people. The three reached safety on the Thai border in the Site II refugee camp after five weeks of walking. They were given bamboo by the Red Cross and other agencies to build a hut. They were very happy to be in safety. One night the camp was invaded by robbers whom she thinks were the Khmer Rouge. The whole section of the camp where she lived, was thrown into chaos. She ran for the forest and when she ran, she heard gun shots. There was a man who followed her into the forest, and crying, Ms. C told me she was raped. When she returned to the hut her mother was crying and told her that her brother had been shot. She was devastated and said that she was very depressed and burned her forehead many times to try and help the pain in her head. The UNHCR foreign volunteers working in the refugee camp helped Ms. C have a nice burial for her brother.

Ms. C, being reserved and soft spoken, did not want to go into detail, but the tears evidenced the pain. She told of how she of ten has bad dreams of that incident in the woods. She saw many people die, but this makes her cry, she says. Though Ms. C is a gentle woman, and I had met her previously, I noticed that she was jumpy and seemed ill-at-ease. She mentioned several times that she has problems with her mind wandering. She gets very angry because she cannot control her mind and, as she said, "goes in every direction." Many times, she said, she thinks that it is because of her that her brother was shot.

Upon resettlement, Ms. C told me that she is adjusting better each day to the culture in America. I thought it was interesting that with Ms. C, as 
with the others interviewed, the nights seemed to be the biggest problem. It is at this time that all the memories return. Ms. C told of how she of ten wakes up in the middle of the night and she is sweating, her heart beating fast, and when she lies there she can remember her bad dream. Every time this happens she has very bad head-aches.

The only real problem Ms. C has now, is her mother. Her mother is having a hard time adjusting to the culture and way of life, and because they both have many sad memories, it is difficult for them to get along. The definite symptoms I noted Ms. C as suffering from were, flashbacks, nightmares, anxiety and guilt, emotional numbness, physical symptoms, interpersonal relationships problems, and hyper-alertness. She constantly mentioned her baby and husband that were lost during this time. She says that when other babies cry, she remembers her own baby. She remembers her babies's birthday, and her husband and her anniversary.

Ms. C cried often during the interview. I tried to let her go at her own pace, and didn't hurry her. I offered support, and sympathy. 


\section{THICK DESCRIPTION \#4}

\section{CASE ONE, SUBJECT A}

Miss A, who had been living in California with her sister, had moved to France during the two-year lapse between interviews. For this reason, her interview was carried out over the telephone. It was recorded on tape (by an answering machine), and immediately transcribed afterwards. The interview lasted only 2.5 hours. She had much to talk about, and was eager to report the changes that had taken place since the last interview. She expressed surprise at hearing from me. I informed Miss A of the continued research of what was previously being studied, and asked for her voluntary cooperation. She agreed, and while she didn't sign a consent form, her verbal agreement is recorded on tape. Issues of confidentiality, limits of confidentiality, and of what was expected of her were explained over the telephone. I established that Miss A felt comfortable with the time, and place at which she was speaking with me, and she confirmed that she was in a private room.

The interview began by asking an open-ended question in regards to her health. She stated that she isn't always well, but that she is doing much better than she had been doing two years ago when I interviewed her. Actually, she reported that her health fluctuates, and now that spring has come to Paris, she is feeling much better. She stated that she really hated the cold, and the cold weather made her feel even worse. She moved to France because she had a relative who lived there and who offered to take care of her. Feeling like she was a burden to her sister in California, and because the fights and disagreements between the two of them only increased since the time of the initial interview, Miss A decided it was best to move to France. She could speak French better than english, and she said that the English 
language had been very difficult for her to learn.

Miss A expressed a lot of appreciation for her relative's children. Because she was in such pain so much of the time, she wasn't able to work, however, over the past two years, she reported that much of her strength had returned, although she hadn't gained weight, and still remained far below the average weight for her height. She said she was able to eat okay sometimes, though, and as a result, she felt a lot stronger. Her motivation for getting stronger, was her relative's children of whom she took care of. She spent nearly every day, dressing them, walking them, and looking after them. She said, "these children give me a big happiness. I wish you could see them. They make me forget about my pain. I feel like they are my children, and my family".

Miss A reported that since moving to France, her fights with her sister have not gotten any better. She said, "I fight with my sister all the time. I don't think that she understands my suffering". She said, though, that her relatives and sister are so close to her. She said, "I don't know what I will do without my family. I will die for sure". Evidently, from the sounds of the interview, Miss A's relatives have been taking very good care of her, and treat her as a member of the family. She sounded very happy to be living there, over the phone.

A major disadvantage to doing this interview over the telephone, was that facial expressions could not be noted, as well as mannerisms and body language during the interview. She was helpful during the initial interview with Miss A, as she evidenced much pain while talking, and at the same time, shedding tears. It was difficult to tell over the phone at what points in the interview Miss A was crying, other than the obvious, open sobs. She openly 
cried once. This was when she told me that she was currently seeing a French psychologist as a suggestion from the initial interview. She had begun to see one for the first year following the initial interview, then after moving to France, she had continued therapy with another therapist. She stated that these sessions were excruciatingly painful, but that she feels that they have helped her. She volunteered all information regarding her therapy and the fact that she was attending. She said that the therapist asked her to "remember many things that are so painful", and that "I of ten cry and feel pain when I remember these things". What she feels is a result of counseling, though, is the fact that she no longer feels the physical pain she had previously felt. (The medical doctors Miss A had been to had not found a cause for this physical pain). She stated that while she will eat even though it is difficult to eat, she feels a lot of pain following a night-mare. The pain lasts for a shorter amount of time, though, and when she is busy during the day, it is easier for her to forget about it. Miss A said, "I hate the night-time. I cry so many times". As a new symptom, Miss A states that she has started to feel numb at certain parts of her body. She said, though, that she feels her french counselor is helping her "to confront the evil Khmer Rouge soldiers".

As persistent symptom that Miss A mentioned, was the guilt she felt over surviving while many of those she loved, did not. She stated that often, little things will trigger memories of her mom, or her sister who died in Cambodia. For example, she said that she could go to the store, and something as small as a laugh, or a certain gesture is enough to "see my family in my mind. I can see my mother and my sister. It is so painful".

Miss A stated that she still gets a lot of head aches, but they are not as 
severe as they had been two years ago. Also, her pain is not as intense. While she had previously felt much pain all over her body, of ten to debilitating degrees, Miss A reported that she rarely felt the pain to this extreme any more.

Miss A said that she really did miss Cambodia so much. Most of all, though, she missed her family, and memories from the old days in Cambodia. She said that,

"I very miss Cambodia. I feel torture when I think about Cambodia and I have not family there. I have a strong feeling I want to live Cambodian life. It is slow and peaceful in Cambodia. It is satisfaction in Cambodia, but this is the old Cambodia. I don't want to live in the new Cambodia".

As an aspect of therapy that Miss A mentioned in the middle of the interview seemingly out of nowhere, was the fact that counseling helped her to know that she cannot forget her memories. She said that before she had tried and tried to forget, but now she knows that she will never forget her memories, no matter how hard she tries, and this attempting to forget is what caused a lot of her pain. She said, "I cannot forget alone. I must have help to remember, then after I remember, the memory isn't so exaggerated in my mind". Miss A said that she has faced a real stigma for going to a counselor, because relatives and friends who hear about it think that she has gone crazy, and this is why she must go. She said that, "I don't want to go because I was shy because going to psychologist mean someone who is lost their mind". But she continues by saying, "I never experience it before, so I don't know, but now I know".

Miss A states that the memories that haunt her come most of ten at night. 
It is at this time that she says that she can't control her mind from remembering. She remembers the killing, a lot. She also has memories when she has a problem, and there is no-one to turn to. She remembers how her parents were always there for her, or how her family would pull together. She said that pictures trigger memories - pictures of other families that are happy. She also mentioned conversations with friends as triggering memories, and flash-backs. At these times, she says that she responds in varying ways. Sometimes she breaks down in tears, other times she just "tries to forget about it", but always there is a hardness, she says, and a great big hurt.

At one point in the interview, Miss A's voice became very quiet, almost reflective sounding, and she said the following,

"I learn that life have many strange experiences. You cannot avoid these experiences. Life is a passing. I am a passenger. I must do what I can do to believe in a power that is in control of my life. I must never be afraid. I never think I have full peace, but I try to gain it. This is how to win the sadness and the problem. Peace mean hope for the future."

Miss A told of how many of her dreams are wrapped around the past, however, when she is feeling better, her dreams also focus on the future. She also said that she has started to trust men again. She said that, from counseling, she has found that she had a lot of anger and resentment towards men, as a result of the Khmer Rouge killings, but now she feels she is able to trust some men in her life, but still doesn't feel like she will be able to ever get married. Miss A has adopted some family, as well, and says that this has made her feel a lot better. She has adopted a grandma in America who had a difficult time 
adjusting there, so she went to Paris, also. Miss $\mathrm{A}$ is close to her adopted grandma, and feels that for the first time since leaving Cambodia, she has someone who understands her, and whom she can trust.

Miss A reported that the biggest problem in adjusting to Paris was the weather. She also was very lonely when she first arrived, but feels better now that she knows more people, and "has extended her family." She also says that she is happier, as her life has become a routine now. But she did say that she feels her moods swing. Miss A reported that she is also currently taking an anti-depressant as medication for depression, but that this dosage has lessened since she initially began therapy a year ago. Miss A could not remember the name of the anti-depressant.

There was some small-talk during the interview, as Miss A inquired as to the welfare of a mutual friend living in the U.S. Other small-talk included talk about a recent program she had gone to at a friend's school, and how she is continuing to practice her english. She also wanted to know if I had a Cambodian recipe from the refugee camp, since she knew I had lived there as a child.

The interview was unstructured and unhurried. During the times in the interview when Miss A audibly cried, I reminded Miss A that she could take her time, and that we were not in a hurry. The interview did not delve heavily into past trauma, as this was already covered during the initial interview two years previously. Miss A did give reference to these traumas, though, many times. At the onset of the interview, I reminded Miss A that I remembered her trauma and the experiences she had related to me. Miss A reported that it is these same experiences, especially the memories of the killing and her escape, that she is dealing with in counseling. 
The interview came to a close when it appeared as all topics had been covered pretty sufficiently, and Miss A stopped talking. Out of curiosity, Miss A asked about me and my studies, and limited self-disclosure was made by me, for the sake of rapport. The interview ended by me thanking Miss $\mathrm{A}$ for her involvement, and for her time. She stated that she enjoyed talking, and would be willing to do it again in another two years, but that it did tire her out. She made the comment that, at the end of our talk, she felt like she did in counseling. Miss A asked my advice in regards to counseling - whether or not I felt it was beneficial. I informed her that I felt she could be the best judge of that. She replied that she did think that it had helped her. 


\section{THICK DESCRIPTION \#5}

\section{CASE ONE, SUBJECT B}

Mr. B, 45-years-old, lives with his wife and three small children in a small two bedroom apartment in Chicago, Illinois. He was interviewed on March 30, 1994. The interview lasted four and a half hours.

Mr. B was asked a few initial open ended questions at which time he proceeded to talk of his own free will unguided by me. The conversation was steered however, towards interview questions that are included in the appendix which were more focused in nature. I attempted to help facilitate the process of remembering experiences and feelings related to focused interview questions while at the same time, not leading him.

Mr. B remembered our interview two years ago and was willing to be interviewed again. He stated, "I think talking to you before was a good thing because when I am done talking I feel better."

I informed Mr. B of the nature of my research and how his participation last time was used. The interview was begun by asking questions pertaining to Mr. B's work, the weather, his family, and aspects of his life at that time. In response to how he is doing, Mr. B stated that he is not doing good, however, he is not doing bad either. He states, "I am just okay, not good, not bad. I think adjustment to life in America is terrible hard. I do not want to go back to Cambodia to live because of all the killing. But America is not my home either."

Mr. B stated that his work is going okay. He works very hard, goes to school and takes care of his children and family. He states that life is very very busy. He says that he has no time for peace. This is in contrast to life in Cambodia. Before the war broke out, life was very peaceful for Mr. B. Mr. 
B states, "American people do not understand the thinking of peace. Everything in America is go, go, go. I miss Cambodia and our belief in some peaceful ways." Mr B also stated that his health is fine and also that of his family. He, his wife and children are all doing Okay.

Mr. B stated that one year ago, January 1993, he had returned to Cambodia to visit surviving relatives and to find friends. He returned to Cambodia as a part of his work. He stated that he really misses Cambodia. The experience of returning to Cambodia was very painful, but rewarding at the same time. Mr. B states, "when I go to Cambodia all the bad memories in my mind that are still recorded in my mind, came to my thoughts. I experienced many feelings when I returned to Cambodia. I hate Cambodia because of the killing, and I hate Cambodia because of many sadness, but I love Cambodia because it is my country. And I miss it and I have many wonderful memories before 1975. At first I was very excited about visiting Cambodia, but after that many bad memories come. This is a big problem for me because in America I forget my bad memories. Good memories of my family and my friends from the old days also come. Memories came when I see my old friends and my old home, and I talk sentimental life in past memory."

Mr. B proceeded to tell of his experiences in visiting Cambodia for the first time since the war in 1975. He compared and contrasted his country between 1975 and 1990. When he returned to Cambodia he stated, he hardly recognized much of the country. Buildings did not look the same and his home did not look the same. The rice fields were not full as they had been when he was a boy.

It was a problem visiting however, because the way $\mathrm{Mr}$. B had learned to cope of the memories and trauma he had suffered was to block it out and 
repress these memories. Visiting Cambodia however, did not allow Mr. B to employ this defence mechanism. He was forced to face the pain and memories he had attempted to repress for all these years. Mr. B recounted how he visited the prison he had been captive in so many years under the Pol Pot Regime. He stated, "Memories of hate came so fast. I have so many memories of hate that I can hardly move when I see this prison."

The most vivid memory that Mr. B says he had to deal with was that of his sister, whose death he feels responsible for. He said that, in America, it was easier to forget, because not many girls remind him of his sister, but in Cambodia, there were many girls who looked like his sister, and reminded him of her.

Mr. B did not stay long in Cambodia. Also he stated to me that he was anxious to return to his wife and children. Mr. B states that America is now home for his children. He said, "They do not know life in Cambodia. My personal belief is that when someone feels peaceful that depends on their custom and how they live. My children grow up in America and they will feel peaceful in America. I do not want to make them go to Cambodia and then to America again because I have this culture change. This culture change is very difficult for me. This culture change makes me many problems and many sadness.

Mr. B then proceeded to inform me of the challenges and difficulties of adjustment to America has posed in the last few years. Mr. B states that the language is still giving him a big problem. While he speaks enough of the English language to get by it is very difficult for him to study and to work day in and day out with a language that he does not quite have a grip on. Mr. B states that there are many other things about the American culture and way 
of life that differ from his traditional value system and views on behavior and attitude towards living and life. One such view is that of success. Mr. B states that in order to live in America you are forced to get caught up in the working world and material items where you must work more to get more. This means that you must work more and then get more. It is a vicious cycle. Buddhist however, value peace. This was a strong value in Mr. B's family of origin. Mr. B states that peace is not available when you are working so much. There are pros about working, however. One such pro is that it helps the person to forget memories.

He stated that he and his wife continue to have nightmares at least three to four times a week. He wakes up in a sweat. These nightmares have continued for the last six years. Mr. B states that he now expects these nightmares to happen. He says that he will not give up fighting them, however. His nightmares have been about the same thing for the last four years. This is of the killing. He states that in his nightmares, he sees his father die and he sees his mother starve to death. The nightmares vary as to who is getting killed, how they are getting killed or how and when they die. They all, however, revolve around the theme of dying and killing. These nightmares are very disturbing to $\mathrm{Mr}$. $\mathrm{B}$ as he states that his wife has similar experiences at night. As a result he tries to stay awake as late as possible until he falls asleep in an exhausted state which he says decreases the chances of getting a nightmare that night.

A theme repeatedly brought up in the interview with Mr. B's family was that his children were his reason for wanting to go on in life and for living. He also stated that he feels very lonely in America. He said, "I don't feel like this country is my home. I have a car, a house and a home but I don't feel that 
my heart lives in this country. My heart is in Cambodia." He continued, "If in thirty years my country is peace, I want to return to Cambodia with my wife and die there. I don't want to die in this country because I am a stranger in this land." He went on to say, "I am glad that I live in America for my children's sake. I think that they will feel like this is their home and that is fine with me. They will grow to have peace with this country. I don't want to disturb that about them. It think it is very difficult to change cultures. I don't want them to have to do the same thing that I have to do which is going from Cambodia to the U.S. It is very hard to change from Cambodia to the U.S. My children do not know life in Cambodia.

Mr. B stated that sometimes he talks about his memories with his wife, however, he never talks about them with anyone else. He also states that during the day if he sees someone or hears a noise it can suddenly bring him back to Cambodia at which time he will have these thought and not "wake up" until sometime later. Sometimes this happens when the time that goes by is a few minutes. Sometimes an hour or two will go by without Mr. B realizing it. Mr. B states, "Every people always thinks that their own culture is better than other. I know this idea, but in my mind I still like my own culture. This is my nature. It is a habit of old people, maybe. I understand every people culture. Here my kids grow up and learn new culture. I don't want to disturb them about this. To me it is very hard to learn the culture. I try to simplify in my own mind how this can be. I simplify so that I will not think about old culture in Cambodia. I will only think about new culture, but I will try to act like old culture in Cambodia.

Mr. B states that he has many Cambodian friends. Sometimes, he says, that they talk about what happened during the Pol Pot time, but not very 
many times. He states that though he has many friends, he still feels very lonely and isolated. He misses Cambodia very much.

I proceeded to follow through with suggestions to see a counselor after our interview two years previously. Mr. B emphatically stated that he did not follow through with these suggestions. And that he would not see a counselor. He stated, "Cambodians do not go to psychologists or counselors. They do not believe in this and they do not know what this kind of person does. It is not the custom to do this. For the Cambodian way, they deal with the problem by religion. Old people go to the temple to pray and talk about Buddha and how to build peaceful mind and memory. The main doctrine of Buddhist teaching say that everything that exists causes suffering. Everything will change. Everyone has suffering. People try to save merit and finally you will rest. Even the rich people have suffering. The poor people have suffering and the sick people have suffering. Everyone will have it at some time in your life. for me personally I try to learn from old experience. I think that I already have my suffering and now I can live the rest of my life by learning from my experience of suffering. I transfer this belief to the Christian doctrine to depend on God. God said that the result of sin is death. Before death comes suffering. I try to understand my suffering through the Bible. This is how the older people deal with it. I am older. I do not know about the young people. I think that they drink and go to the bar. I think that the older people go to the monk and to the temple. Every four times a month, the temple has a celebration of holy days. The people go to the temple to pray and eat. Even the monk as suffering. Usually I don't talk about my suffering, my memory and the pain of my mind to somebody because if I talk to someone that person is burdened with the problem. Then the problem becomes bigger. So I try to 
forget about it."

Mr. B states that he has tried many methods to get rid of the memories and to get rid of the pain. He states that as long as he looks to God and gives his burden to Him, he feels more relaxed. He says that if forgets to pray to God, it is more terrible. However, God gives him peace. Mr. B says that ever since arriving in America, he has problems in dealing with his anger. Occasionally he feels very angry towards his wife and children. He does not know why. He is not sure where these anger come from. He does not remember feeling these intense feelings of anger when he was a child or when he was younger living in Cambodia. He says that they have resulted ever since he has seen these killings and experienced a lot of pain. Mr. B has not dealt with this anger. He continues to find peace and a way to live with this anger. However, Mr. B says that sometimes his anger becomes so much that he feels immobilized. He is not able to perform his work or think straight.

Another disturbance that $\mathrm{Mr}$. B described was that of remembering and reliving the scenes of his father's death. Mr. B states that these scenes are played over and over in his mind. Often times he must do something quickly to get rid of these scenes in his mind such as getting up and move and eat, go talk to somebody. He says that he will do anything and everything to get these scenes out of his mind at the time.

At the time of our last interview in 1991, Mr. B evidenced physical symptoms such of a persistent sniffle that he has had ever since he arrived in Thailand. Mr. B stated at that time that he had been to see three medical doctors who had found no physiological reason for the sniffle. During the present interview, Mr. B continued to sniffle and I asked about this. Mr. B stated that he had been to another doctor who also could not find any 
physiological causes for the sniffle. Mr. B says that he has now learned to accept it. However, when asked if it worsens during memories of trauma, Mr. B confirmed this, saying, "when I have some memories, especially during the day, my sniffle becomes very bad. I feel like I have a cold. My head hurts. My head feels like hurting and aching. I have this sniffle. He continued saying, "I have tried many medicines from the drug store, but nothing can help me. They only make my head hurt worse. They make me sick in other ways." Mr. B says that this is another reason that it is so important for me to be trying to forget. He also states that before he was concerned about this. His wife was concerned, but now they have learned to accept it. Mr. B said though, that he hopes that these problems will go away in the future.

On discussing the future, Mr. B said that he has a lot of hope. He has hope for his children. He has hope that his children will lead good lives. He has hope to return to Cambodia. He has hope that Cambodia will become peaceful someday. Mr. B used the analogy with me of going on a trip and packing a suitcase. He asked me if I had been on a trip. I said, "yes". And he said, "when you went, even if you stayed for along time, you stayed in a hotel. You brought in your suitcases." I said, "yes, I confirm this." Mr. B proceeded then to tell me that even though I took the things out of my suitcases, the suitcases were always there. I never totally unpacked. Mr. B then said, "it is the same way for him in America. While he has settled here by raising his children here and getting a job, he has not fully unpacked himself. He saves a little bit of himself for Cambodia because he looks to the future hoping that in the future Cambodia will be peaceful and a place that he can return to."

As far as resettlement goes, Mr. B has noticed a difference in the last 
two years in how he has been able to adjust to life in America. I inquired about this. I only made a few direct questions during the interview and this is one of them. I directly asked Mr. B how things have changed for him in becoming better or worse in the past two years since I interviewed him in 1991. He stated that he feels that he is more comfortable in America. He is more familiar with customs, services, people and expectations. But he says that this has not made it better. He said, "not even one day can pass without me remembering life in Cambodia." He also stated that along with these memories of a peaceful life in Cambodia when he was a child comes the memories of suffering and killing from Pol Pot and Pol Pot's rule. Mr. B also stated that he does plan to visit Cambodia again in the future and that he has managed to keep in contact with a few friends there.

In discussing the memories of the killing, $\mathrm{Mr}$. B states that he tries to stop these memories before they become too painful. On Occasion however, he states that he has felt that his heart race and he feels panicky. He then breaks out in a sweat at these memories. He says that this only occurs when he allows his mind to think too much about the pain and sadness of the past. Mr. B says that he does not know anyone who has gone to counseling. He would not know what to do or how to deal with it if he did.

In response to a question as to what other Cambodians did when they had painful memories. When they were panicky, were depressed, had bad dreams. Mr. B offered a few traditional medicine ideas such as putting pressure on the forehead, or taking some traditional herbs or teas. 


\section{THICK DESCRIPTION \#6}

\section{CASE THREE, SUBJECT C}

Ms. C, 30 years old, continues to live in Phoenix Arizona, she is currently living with some Cambodian friends who were also able to escape with her at the time of Pol Pots rule. Ms. C, recalled our interview two years ago and was happy to participate. This interview lasted $31 / 2$ hours and proved to be very emotional. Prior to beginning the interview, Ms. C was briefed on confidentiality, and the nature of the recent consent form was obtained. She appeared willing and eager to talk and participate. However, she did apologize several times for her language. It was thought however that Ms. C possessed a good english vocabulary.

The interview was begun by asking Ms. C how she was currently doing. This lead Ms. C into a discussion of her present work. She told about her work, her health, and about the studies she was taking. Ms. C continues to go to school and work long hours. She states that she is feeling OK and her health is not too bad although she does get extremely ill and sick during certain times. Ms. C refers to these times as "sick memory times". She can not stop obsessing and thinking about memories and killings in Cambodia when she was a child. At these times Ms. C states that she is paralyzed and "I can not go to work. I can not get out of bed. All I can do is stay in my bed and cry." Ms. C states that these episodes happen only about once every other month. And they usually last anywhere from two to seven days. Miss C states that she tries desperately to put a lot of energy towards trying to keep these pains down to a minimum or to keep them from happening. Ms. C states that the worse times for her are at night when the memories come strong. It is then that she remembers her child, and all aspects of her child. Her child and late 
husband were mentioned repeatedly through-out the interview. Ms. C said that it was very difficult for her to fall asleep at night. Often times it takes her hours to fall asleep because of these memories. She then starts worrying about getting the memories. Her worry keeps her from sleeping at night as well.

Ms. C also brought up the death of her sister during the Pol Pot Regime rule. She had not mentioned the death of her sister in our first interview in 1991. She stated that she had not remembered the death of her sister at that time. She had not remembered her sister at all. Ms. C's mother had never mentioned her sister to her. The name had never been brought up. There was nothing to remind her of her sister until a cousin was resettled in America in 1992. At this time the cousin talked about Ms. C's sister. She denied that she had a sister. Later she could remember a few things about the sister. But after talking to this cousin, more and more memories came back to her. She was then able to recall the traumatic death of her sister of which Ms. C had an active part in. She even remembers having to dig her sister's grave. The trauma, she states, was so severe that she requested that her cousin not tell her everything all at once.

During our interview as Ms. C stated these facts to me she grew extremely emotional and broke down into violent sobs. At this time I offered sympathy and support to her. It took Ms. C about twenty minutes for her to regain her composure so that we could carry on in talking. The environment of the interview was very relaxed and non stressful as we were not in a hurry. Following Ms. C's breakdown and composure, we moved into a more impersonal subject of her resettlement.

Ms. C was able to talk about her resettlement. She told me how she is 
continuing to go to school and struggle with her classes all the while she works full time at a job. She informed me that she loves her work. She likes being resettled in America. She has no desire to return to Cambodia anytime soor. From reports from friends who have visited Cambodia, she has learned that Cambodia is still unstable and not a safe place to live. She said that she does not want to return to a country that treated her so badly and that has caused her so much pain and trauma. She misses the peacefulness of the country side of Cambodia. She stated, "I miss my childhood time, my friends, the school and the happiness with my family. I do not miss the killings or all of the bad and terrible things that happened to me when I lived under Pol Pot Regime." Ms. C states that though she has friends in America, she feels lonely everyday. Even though she has many friends who write and telephone to her at home, she still feels lonely. She said that there are times when she cries so hard that she cannot cry. When she cries like this, she gets very ill and falls into a state of despondency. She stated, "When I cry so much, my head aches, my body feels sick. I feel like I cannot move, eat and want to stop thinking. Many times I feel like I want to kill myself. I do not know why all this sadness happened to me. Why can't I forget about these memories? I don't know why it is me that has to live this way. Why don't the other people have to experience things like I did."

Ms. C states that her dreams bother her greatly. She of ten dreams about her grandma. During these dreams, her grandma comes to her and calls her to come and sit on her lap. She wakes up from these dreams crying because she recalls her grandma's love and tender ways. She said, "I miss my grandma so much."

Ms. C said that many times she tries to keep herself very busy so that 
she will not remember the trauma of the past. She said, "I know so many sad things but I try to forget them during the day. To do this I try to keep myself very busy. When I watch a movie and read a book I think about another life instead of my own life." She also stated, "Many of my Cambodia friends tell me to forget my memories. They tell me that they also forget their memories. I tell them that I cannot forget my memories because this memory affects every part of me. Actually I think that my friends also have some memories that they suffer from. They tell me about the bad dreams that they had. We do not talk about this with each other because we feel ashamed to talk about it. She also stated, "Sometimes I think that I am crazy because I think too much. If I think about the sadness and the people who die then I will become crazy. I am afraid sometimes that I will become crazy."

On her own Ms. C came back to the subject of her sister and her death. She stated that since learning about it, remembering these memories, Ms. C has felt a tremendous amount of guilt. She wonders why her sister died and she did not die. She feels like she could have done more to help and save her sister. She said that many of her dreams are now about her sister and the way her sister died. She also said, "sometimes my mind thinks about something that I told to my sister or grandma before they died. I keep thinking about this thing over and over again. For example, before my sister died, I told her that she is a coward and a chicken. Now I do not think that this is true. But I cannot tell my sister now. There are many things that I want to tell my grandma also. But I cannot tell her because she is gone." She stated, "I am proud to be my mom and my dad's children. I am not proud to be a slave to the communist people. I am not proud to have had to eat insects on the ground. I do not like to be on the same level as the animals." 
I asked Ms. C how she is able to keep going and how she is able to deal with the trauma and pain. She stated that the biggest thing that keeps her going is thinking about how tomorrow will be better and looking at where she will be five years from now. She states that she wants to have a new family. She wants to someday get married again. She hopes that she will someday not have the pain of the memories.

Ms. C told me that in 1984 she arrived in the Nong Samet Refugee Camp along the Thailand Cambodia border. It is at this time that the attacks took place where she was raped. She refers to this in the interview. She said, "This memory is not as bad as some other memories that come to mind. The worst memory is of my sister." She vows to herself that she will not run away from her sister's bones or where she is buried. She told me that while she is happy to be in America; she loves America and she would not want to go back to Cambodia, things have been very difficult for her. She does live with friends and is involved in a type of Cambodian community where she has a lot of Khmer acquaintances and friends. However, as I stated earlier, she still feels lonely. She said, "My job and friends are okay, but there are some things that I did not prepare myself for that has happened to me in this country. She said, "I tried to prepare myself for America. I knew that America would be different from Cambodia. But I don't think I could prepare myself enough until I came here. When i first arrived it was very difficult to earn money. I only got $\$ 100$ from the US resettlement services. I started working as a seamstress. I have been able to work up to the level where I am at now which is designing patterns as a typographic artist." She went on to tell me that she has been able to gain a little weight since she has been in America. During the Pol Pot Regime she had lost a lot of weight and was very 
skinny. She wonders why she did not die when so many of her friends and family died.

At the end of our interview, Ms. C. stated that she hopes to return to Cambodia to visit someday, but not until Cambodia has peace. She is continually trying to make a home in America though many things are very different. She has seen that America has a lot of conflict and chaos. She said, "everyone in America is in a big hurry. No one has time to stop to think about the peaceful things. They don't have time to stop and by quiet. I like this society because I like to be busy. If I think about the peaceful things, my mind will remember the suffering in Cambodia. I do not want this to happen." Ms. C states that she often feels like she is a pilgrim. She is traveling and traveling and traveling. She doesn't know where she'll go but she still feels like a pilgrim. She said, "I do not want to plan my life because when I was young in Cambodia I had many dreams with my family, many goals and many plans. Nothing happened to those dreams and now all that is destroyed. She states that in order to keep herself from being too disappointed, she does not plan at all now. She allows fate to take it's natural course to determine what will happen to her in the future.

Ms. C said that she does not want to die because she has some family and many friends. She wants to live for them. While her immediate family, her husband and child were taken from her, she hopes that she can have another family in the future. Until that time, she sates, "There are many people whom I consider like my family. These people are my friends who live near me. I enjoy helping them. I want to make their lives better in some way."

Ms. C stated that in an effort to deal with the culture clash and differences that she has had to face upon resettlement, she has tried to take 
a 50/50 approach. This is where part of her will be American and accept the American things and part of her will be Cambodian and accept the Cambodian way of life. She states that following our initial interview, she began thinking about how she will deal with stresses of living in America. She sat down and made a list of what she really appreciates about the Cambodian customs and way of life and what things from the American way she wants to make apart of her life. So now she feels that she is trying to be $50 / 50$.

When war came to Cambodia, people changed. They had to steal to survive. They had to be dishonest and lie in order to not die and become part of the Pol Pot Regime. After 1980 foreign culture came into Cambodia. There is a lot of ways where the old Cambodian customs have disappeared. Now religion does not mean so much anyone. Many people do not go to the temples. The customs of the girls have changed because the girls can date any guy now. They are more free than when Ms. C was growing up.

"In Cambodia you cannot be honest. You cannot trust everyone around you. When I came to America it was hard for me to talk with anyone because I was afraid they would hurt me."

Near the end of our interview I followed through on whether Ms. C. had sought counseling after our first interview in 1992. She stated that she had not followed through with counseling. She said that most Cambodian people do not go to a counselor because they think that their problems is their own business. She said, "Why would you go to a counselor to give your problems to someone else. Then you would also trouble that person. Why try to make the problem worse by giving more people your problems. If you do not like your problems, then why would you want to give your problems to someone else? Ms. C. states that she could talk to a counselor but she does not know what 
to expect from a counselor. She said, "If I go to a counselor, I do not know what to do or what to say or who to be." She said that she prefers to keep her problems in her own heart and perhaps talk to her mother about them. While she has had difficulty in dealing with her mother, she said that sometimes they can talk about problems, but this is not of ten.

Our interview proved to be very exhausting and lengthy. Following the interview, Ms. C. offered me some fruit and drink as is the Asian custom. We continued to talk during this meal. This time which was about an hour, proved to be a form of wrapping up the interview, or closure. I attempted to guide Ms. C. away from discussing personal and highly emotional areas to more external aspects of her life, such as adjustment issues and her current studies. We also ended by discussing people in her community and what they are doing. She told me what areas she hopes to be involved in the future. Ms. C. proved to be very cooperative and eager to talk. She expressed appreciation at the end of the interview for my talking with her. The interview was then closed by my departure and in my expressed appreciation for her participation. 


\section{REFERENCE LIST}

American Psychiatric Association. (1987). Diagnostic and statistical manual of mental disorders (3rd ed.). Washington, DC: Author.

Becker, E. (1986). When the war was over. New York: Simon and Schuster.

Bromley, M. A. (1987, May-June). New beginnings for Cambodian refugees--or further disruptions. Social Work, pp. 236-239.

Brooks, J. (1989). Nightmares-dreams of refugees. The Daily Breeze, $\underline{2}$, $1-8$.

Carlson, E. B., \& Rosser-Hogan, R. (1991). Trauma experiences, posttraumatic stress, dissociation, and depression in Cambodian refugees. American Journal of Psychiatry, 148(11), 1548-1551.

Chelminski, R. (March 1994). The new killing fields. Reader's Digest, pp. 107-112.

Centers for Disease Control. (1992). Washington, DC, U.S.A.

Costigan, K. (1989). Haunted by the past. Savy Woman, 10, 98-102.

Eth, S., \& Pynoos, R. (1985) Post-traumatic stress disorder in children. Washington, DC: American Psychiatric Press.

Evans, G., \& Rowley, K. (1984) Red brotherhood at war. New York: Simon and Schuster.

Figley, R. C. (1989). Helping traumatized families. San Francisco: JosseyBass.

Forman, S., \& Havas, S. (1990). Massachusetts' post-traumatic stress disorder program: A public health treatment for Vietnam vets. Public Health Reports, 105 (2), 172-179.

Foy, W., Sipprelle, C., Rueger, B., \& Carrol, M. (1984). Etiology of posttraumatic stress disorder in Vietnam veterans: Analysis of preliminary, military, and combat exposure influences. Journal of Consulting and Clinical Psychology, 52, 79-87.

French, L. (1990). Displaced lives. Bangkok, Thailand: Craftsman Press. 
Friedman, F. (1990). Expanded delivery system needed for PTSD. Hospitals, $\underline{6}, 44-45$.

Goldberg, J., True, R., Eisen, A., \& Henderson, G. (1990). A twin study of the effects of the Vietnam war on post-traumatic stress disorder. Journal of the American Medical Association, 263(9), 1227-1232.

Goldfield E., Mollica, R., Resavento, H., \& Karaone, V. (1988). The physical and psychological sequelae of torture: Symptomatology and diagnosis. Journal of the American Medical Association, 259(18), 2725-2729.

Green, B., Grace, M., Lindy, J., Gleser, G., \& Leonard, A. (1990). Risk factors for PTSD and other diagnoses in a general sample of Vietnam veterans. American Journal of Psychiatry, 147(6), 729-733.

Guba, E. (1978). Toward a methodology of naturalistic inquiry in educational evaluation. (CSE Series in Evaluation Monograph No.8). Los Angeles: University of California, Los Angeles, Center for the Study of Evaluation, Graduate School of Education.

Guba, E. (1981). Criteria for accessing the trustworthiness of naturalistic inquiries. Education, Communication and Technical Journal, 29(2), 75-92.

Guba, E., \& Lincoln, Y. (1981). Effective evaluation. San Francisco: Jossey-Bass.

Herman, J. L. (1992). Trauma and recovery. USA: Basic Books.

Ith, C. (1993). Resettled Cambodians. Unpublished manuscript.

Kiljunen, K. (1985). Power politics and the tragedy of Kampuchea during the seventies. Bull Concerned Asian Scholars. 1749-1767.

Kinzie, D., Fredrickson, H., Ben, R., Fleck, J., \& Karls, W. (1984). Posttraumatic stress disorder among survivors of Cambodian concentration camps. American Journal of Psychiatry, 141(5), 645650 .

Krathwohl, D. (1993). Methods of educational and social science research. White Plains, NY: Longman.

Krich, J. (1990, October). Culture crash. Mother Jones, pp. 24-26, 52-53.

Kroll, J., Habenicht, M., Mackenzie, T., Yang, M., Chan, S., Vang, T., Nguyen, T., Ly, M., Phommasouvanh, B., Nguyen, G., Vang, Y., Souvannasoth, L., \& Cabugao, R. (1989). Depression and posttraumatic stress disorder in Southeast Asian refugees. American Journal of Psychiatry, 146(12), 1592-1597. 
Maanen, J. (1983) Q Qualitative methodology. California: Sage Publications .

McLeod, B. (1985, April). Cambodia: The cruelty lingers. Psychology Today, p. 12 .

McWilliams, C., \& Piatrowski, H. (1990). The world since 1945: A history of international relations (2nd ed.). Boulder, CO: Lynne Rienner.

McNulty, S. (1994, March 20). Cambodia claims Khmer Rouge headquarters captured. The Nation, p. 7.

Miles, B. (1983). Qualitative data as an attractive nuisance: The problem of analysis. In J.V. Maanen (Ed.), Qualitative Methodology (pp. 117134). Beverly Hills, CA: Sage.

Ministry of Health, Cambodian Government, with assistance from World Health Organization (1992). Phnom Penh, Cambodia.

Mollica, R., Wyshak, G., Lavele, J., Truong, T., Tor, S., \& Yang, T. (1990). Assessing symptom change in Southeast Asian refugee survivors of mass violence and torture. American Journal of Psychiatry, 147(1), 83-88.

Muncy, S. (1988). Community mental health and family services, Inc.: A program description. Passage, pp. 43-45.

Mysliwiec, E. (1988). Punishing the poor: The international isolation of Kampuchea. Oxford, United Kingdom: Oxfam.

Omery, A. (1982). Phenomonology: A method for nursing research. Advances in Nursing Science. pp. 49-63

Patterson, J. (1989). Study on the resettlement of the Indochinese people in Canada. Canadian Government Social Service Department. (1-2).

Patton, Q. (1980). Qualitative evaluation methods. Newbury Park, CA: Sage.

Ponchaud, R. (1978). Cambodia year zero. New York: Holt, Rinehart, and Winston.

Psychiatric Intervention after Disaster. (June 1989). The Lancet, p. 138.

Raymond, A. (1988). Study says memories of violent death linger in survivors, trigger psychosocial problems. Journal of the American Medical Association, 259(24), 3524-3525.

Robinson, C. (1980, March). Special report: Physical and emotional health care of Indochinese refugees. Available from Indo-Chinese Refugee Settlement Unit, 8 York Street, 4th floor, Toronto, Ontario, Canada. 
Rumbaut, B. In T.C. Owan (Ed.), (1985). Southeast Asian mental health treatment, prevention, services, training, and research. Washington, DC: National Institute of Mental Health.

Sandrick, K. (1990). Expanded delivery system needed for posttraumatic stress. Hospitals, pp. 44-45.

Schanberg, S. (1983). The killing fields. London: Weidenfield \& Nicolson.

Shawcross, W. (1979). Sideshow: Kissinger, Nixon, and the destruction of Cambodia. New York: Simon and Schuster.

Study finds $90 \%$ of survivors suffer from PTSD. (1989, July 15). The Lance, p. 138.

Sue, D. W. , \& Sue, D. (1990). Counseling the culturally different (2nd ed.). New York: John Wiley \& Sons, Inc.

Szymusiak, M. (1986). The stones cry out: A Cambodian childhood 19751980. (L. Coverdale, Trans.). London: Sphere Books. (Original work published 1984).

Tesch, R. (1990). Qualitative research: Analysis types and software tools. London: Falmer.

Toole, J., \& Waldman, J. (1993). Refugees and displaced persons: War, hunger, and public health. Journal of American Medical Association, 270 $(5), 600-605$.

Uba, L., Chung, C. (1991). The relationship between trauma and financial and physical well-being among Cambodians in the United States. The Journal of General Psychology, 118(3), 215-225.

UNICEF. (1990). Cambodia: The situation of children and women. Phnom Penh: UNICEF, United Nations Children's Fund, Office of the Special Representative.

United Nations. (1993). Kampuchean humanitarian assistance program. New York, United Nations.

Whitaker, M., Clifton, T., \& Moreau, R. (1985, April 8). Return to the killing fields. Newsweek, pp. 8-13.

Wicassio, P. (1985). The psychological adjustment of the Southeast Asian refugee. Journal of Cross-Cultural Psychology, 16(2), 153-173.

Williams, C. L., \& Westermeyer, J. (Eds.). 1986. Refugee mental health in resettlement countries. Washington, DC: Hemisphere. 